\title{
DEMANDA SOCIAL, PLANEJAMENTO E DIREITO À EDUCAÇÃO BÁSICA: UMA ANÁLISE DA REDE ESTADUAL DE ENSINO PAULISTA NA TRANSIÇÃO 2015-2016*
}

\author{
Fernando Luiz CÁssio ${ }^{1}$ \\ Leonardo CrochiK ${ }^{2}$ \\ Maria Clara Di Pierro ${ }^{3}$ \\ Sergio Stoco ${ }^{4}$
}

\begin{abstract}
RESUMO: Este texto procurou contribuir com o debate contemporâneo a respeito dos modelos de gestão da educação pública, apresentando dados empíricos e análises sobre a política recente de atendimento à demanda escolar do governo estadual de São Paulo. Demonstra que, embora reflexos da redução da fecundidade em coortes da populaçáo em idade de escolarização obrigatória possam ser observados, as matrículas nas escolas públicas estaduais tendem à estabilidade, não havendo retração de procura que justifique o fechamento de ciclos e unidades escolares pretendidos pela reorganização escolar proposta em 2015 e suspensa após protestos estudantis. Reúne, também, evidências de que a lógica que presidiu a reorganizaçáo continua vigente na gestão da demanda. A análise da evolução do tamanho das turmas entre 2015 e 2016 revela aumento do número de alunos por classe em todas as etapas da educaçáo básica, em contradição com diretrizes do Conselho Nacional de Educaçáo e em detrimento das condiçóes de ensino e aprendizagem reivindicadas por estudantes e educadores.
\end{abstract}

Palavras-chave: Direito à educação. Política educacional. Demanda escolar. São Paulo (estado).

\section{SOCIAL DEMAND, PLANNING, AND THE RIGHT TO BASIC EdUCATION: AN ANAlysis of THE SÃo PaUlo State EdUCATION SYSTEM DURING THE 2015-2016 TRANSITION}

ABSTRACT: This article aimed to contribute towards the contemporary debate regarding management models for public education. It presents empirical data and analysis regarding recent policies for attending the demand for schooling of the São Paulo State government

\footnotetext{
*Artigo resultante de pesquisa exploratória interdisciplinar, desenvolvida no âmbito da Rede Escola Pública e Universidade.

${ }^{1}$ Universidade Federal do ABC - Santo André (SP), Brasil. E-mail: fernando.cassio@ufabc.edu.br ${ }^{2}$ Instituto Federal de São Paulo - São Paulo (SP), Brasil. E-mail: crochik@gmail.com

${ }^{3}$ Universidade de São Paulo, Faculdade de Educação - São Paulo (SP), Brasil. E-mail: mcpierro@usp.br

${ }^{4}$ Universidade Federal de São Paulo - Diadema (SP), Brasil. E-mail: brestoco@outlook.com

DOI: 10.1590/ES0101-73302016167297
} 
administration. It demonstrates that, although one can observe reflexes of the fertility reduction in cohorts of the obligatory schoolage population, enrollment in state public schools tends to be stable, with no retraction that would justify the closing of schooling cycles or units, which is the intention of the schooling reorganization proposed in 2015 that was suspended after students' protests. It also gathers evidences that the logic that directed the reorganization continues to hold good regarding demand management. The analysis of the evolution of how the sizes of the classes are distributed from 2015 to 2016 reveals, in all the stages, the increasing number of students per class in contradiction to the directives of the National Council for Education and in detriment to the conditions for teaching and learning warranted by students and educators.

Keywords: Right to education. Education policies. Schooling demands. São Paulo (state).

\section{LA DEMANDE SOCIALE, LA PLANIFICATION ET LE DROIT À L'ÉDUCATION DE BASE: ANALYSE DU SYSTÈME EDUCATIF DE L'État de SÃo PaUlo AU COURS de LA TRANSITION 2015-2016}

RÉSUMÉ: L'article vise à contribuer au débat contemporain sur des modèles de gestion pour l'éducation publique. Il présente des données empiriques et des analyses concernant les récentes politiques pour assister à la demande d'enseignement de l'administration du gouvernement de l'état de São Paulo. Il démontre que, bien que l'on peut observer les réflexes de la réduction de la fécondité dans des cohortes de la population en âge scolaire obligatoire, le nombre d'inscriptions dans les écoles publiques de l'état tendent à être stables, sans retrait ayant été observé qui justifierait la fermeture des cycles de scolarité ou d'unités d'enseignement, ce qui est l'intention de la réorganisation de l'enseignement proposée en 2015 qui a été suspendue après les protestations des étudiants. Il rassemble également des preuves que la logique qui a dirigé la réorganisation continue en vigueur à la gestion de la nouvelle demande. L'analyse de l'évolution de la façon dont les tailles des classes ont été distribuées entre 2015 et 2016 révèle, dans toutes les étapes, l'augmentation du nombre d'élèves par classe en contradiction avec les directives du Conseil national pour l'éducation et au détriment des conditions d'enseignement et d'apprentissage réclamés par les étudiants et les éducateurs.

Mots-clés: Droit à l'éducation. Politiques d'éducation. Demandes de scolarisation. São Paulo (état). 


\section{Introdução}

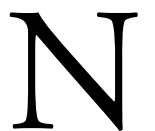

o último trimestre de 2015, a sociedade paulista foi duplamente surpreendida. Primeiro, por uma proposta de reorganização da rede de escolas de ensino básico mantidas pelo poder público estadual; e segundo, pela reação dos estudantes secundaristas a esse intento de reforma, com a ocupação de mais de uma centena de unidades de ensino e a realizaçáo de dezenas de manifestaçōes públicas duramente reprimidas pela polícia e pela burocracia governamental.

O inesperado apreço e cuidado da juventude paulista por escolas públicas deterioradas e desprovidas de atrativos mobilizou a solidariedade de diversos segmentos sociais e cativou a simpatia da opiniáo pública, ao mesmo tempo em que os meios de comunicação e os cientistas sociais tentavam compreender as inusitadas formas de mobilização e de organização estudantil horizontal, e a intensa participação feminina nesse movimento.

Após dois meses de conflito, face às sentenças judiciais que impediram a desocupação forçada das escolas e proibiram seus fechamentos, e na tentativa de minimizar o desgaste político revelado pelas pesquisas de opiniāo, o governador do Estado de São Paulo viu-se obrigado a recuar, suspender a chamada "reorganização da rede estadual de ensino"2 e aceitar a demissão do secretário que estivera à frente da iniciativa.

Caso tivesse se consumado, essa "reorganização" da rede escolar — planejada sem qualquer consulta aos interessados e à revelia do princípio da gestáo democrática - teria levado, segundo dados da própria Secretaria da Educação do Estado de São Paulo (SEE-SP), ao fechamento de 94 escolas (cerca de 1,6\% da rede) e à reestruturaçáo dos ciclos de outras 754 unidades de ensino (cerca de $13,3 \%$ do total $)^{3}$, impactando diretamente a vida escolar e funcional de $311 \mathrm{mil}$ alunos (com repercussões sobre suas famílias), 71 mil docentes e um número não estimado de funcionários administrativos e operacionais.

Os argumentos alegados para medida dessa envergadura eram basicamente dois: primeiro, de que escolas organizadas em ciclo único facilitariam a gestão, e estudantes de escolas assim organizadas teriam melhor rendimento escolar (aferido em avaliaçóes externas padronizadas); e, segundo, de que mudanças demográficas estariam reduzindo a demanda por ensino básico, sendo oportuno redimensionar a rede escolar em conformidade com essa tendência.

$\mathrm{O}$ primeiro desses argumentos, precariamente sustentado em estudo divulgado a posteriori pela SEE-SP por demanda de órgãos de imprensa (SÃO PAULO, 2015c), foi prontamente contestado em uma análise realizada por pesquisadores da Universidade Federal do $\mathrm{ABC}$, que revelou os equívocos metodológicos e a ausência de evidências científicas que sustentassem a suposta correlaçáo positiva entre a organização escolar em ciclos únicos e um melhor desempenho escolar dos estudantes (PÓ et al., 2015) ${ }^{4}$. 
O segundo argumento, calcado em eventuais relaçóes entre dinâmica demográfica e demanda por ensino básico no Estado de São Paulo, será objeto da primeira parte do presente artigo, que pretende também discutir as evidências de que os objetivos e a lógica que presidiram a proposta de reorganização da rede escolar paulista continuam a vigorar, orientando o planejamento e a gestáo da rede física e da demanda por vagas, em detrimento das condiçóes de ensino e aprendizagem reivindicadas por estudantes e educadores.

\section{Dinâmica demográfica, demanda e atendimento no ensino básico no Estado de São Paulo}

Em uma curta nota técnica de 2015, a Fundação Sistema Estadual de Análise de Dados (Seade) assinalou que, devido à queda da fecundidade, a população de 6 a 17 anos vem diminuindo no Estado de Sáo Paulo a um ritmo de 0,8\% ao ano desde 2000 — tendência intensificada no período mais recente, de modo que desde 2008 essa redução ocorre a uma taxa de 1,3\% ao ano, o que levaria à retração da demanda por ensino básico (SEADE, 2015). Analisando os dados do Censo Escolar de 2000 a 2014, o órgão constatou a diminuição das matrículas na rede estadual de ensino, atribuída à combinação da mencionada dinâmica demográfica com a municipalizaçáo do Ensino Fundamental e com a expansão da rede privada.

Inicialmente, é preciso problematizar a noção de demanda escolar que subjaz a essa linha de argumentação. A Fundação Seade menciona explicitamente que o grupo de 6 a 17 anos seria o "segmento elegível para o ensino básico". Entretanto, a legislação assegura o direito à educação básica gratuita também aos jovens e adultos que não tiveram acesso ou não o concluíram na idade considerada ideal, o que implica computar na demanda tanto as pessoas que frequentam o ensino básico com defasagem na relação idade-série ideal (seja na modalidade regular ou na Educação de Jovens e Adultos - EJA) como as pessoas com escolaridade básica incompleta que se encontram fora da escola. Segundo a Pesquisa Nacional por Amostra de Domicílios (PNAD) de 2014, o Estado de São Paulo tinha fora das escolas 37.640 crianças e adolescentes de 6 a 14 anos e 245.467 jovens entre 15 e 17 anos; e dentre os que as frequentavam, uma parcela significativa não se encontrava na idade-série ideal, devido a interrupçóes ou à reprovação escolar ${ }^{5}$.

Portanto, as análises de demanda e as políticas de atendimento escolar não podem se ater à população matriculada, mas considerar e atuar sobre os fatores econômicos, sociais ou culturais que dificultam ou impedem o acesso à escola, como o trabalho infantojuvenil ou a gravidez na adolescência, por exemplo ${ }^{6}$.

É preciso ponderar também o fluxo escolar, dependente dos índices de reprovação e abandono escolar que, somados, representavam no conjunto das redes de ensino paulistas 4,8\% no Ensino Fundamental e 16,3\% no Ensino Médio, 
em 2013, sendo especialmente elevados na rede estadual, respectivamente 6,1 e $18,5 \%$ naquele ano (SÃO PAULO, 2014).

É fato que a rede estadual de ensino perdeu milhóes de matrículas no transcorrer das duas últimas décadas, e que isso não se deve apenas às mudanças demográficas, mas também às transferências entre as redes de ensino. $\mathrm{Na}$ segunda metade da década de 1990 e princípio dos anos 2000, o movimento dominante foi o de municipalização do Ensino Fundamental; na última década, a diminuição de matrículas na rede estadual de ensino deve-se principalmente à progressiva privatização do ensino básico decorrente da fuga dos setores de renda média para a rede particular, uma das consequências da deterioração das condiçóes de ensino e aprendizagem nas redes públicas, sobretudo a estadual, e seu consequente desprestígio 7 .

Considerado o período de 2000 a 2014, a tendência das matrículas nos Anos Iniciais do Ensino Fundamental é de estabilidade no patamar de 3 milhóes de estudantes, com o aumento da participação das redes municipais e privada, e retração da rede estadual (Figura 1).

\section{Figura 1}

Evolução das matrículas nos Anos Iniciais do Ensino Fundamental, por dependência administrativa, no Estado de São Paulo, 2000-2014.

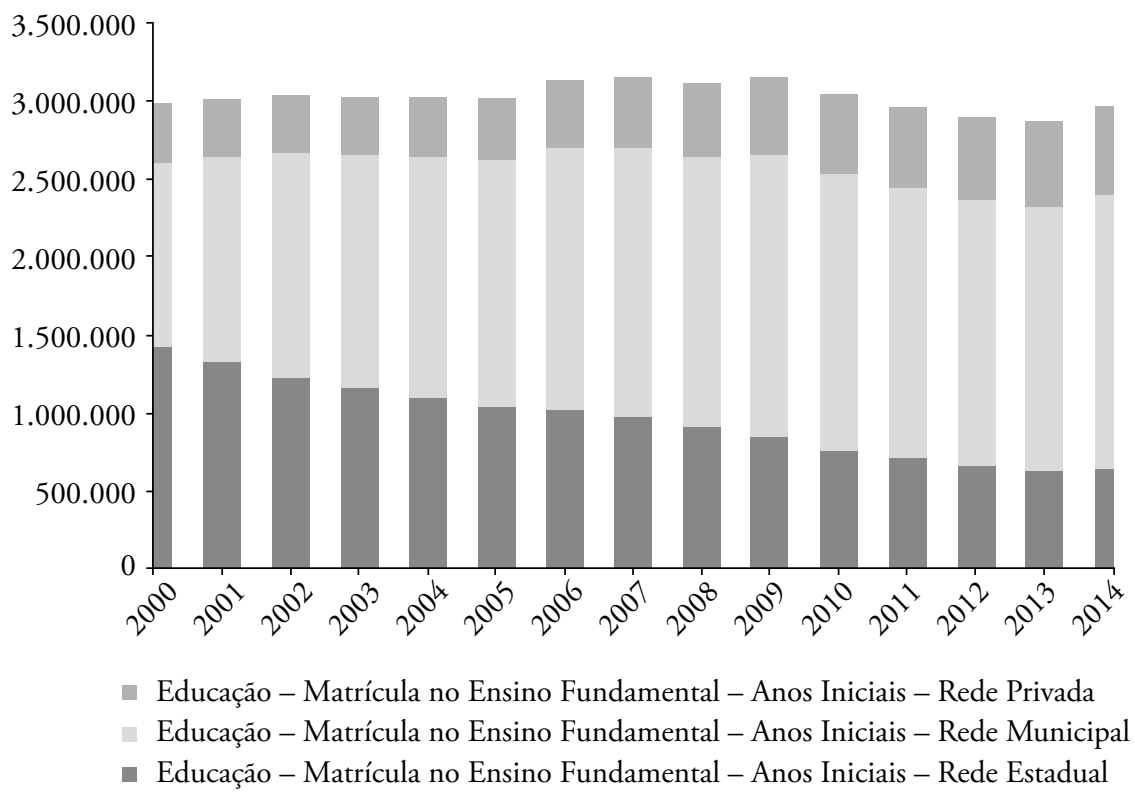

Fonte: Inep, Censo Escolar e Fundação Seade. 
As estatísticas vitais para a populaçáo infantojuvenil são coerentes com o comportamento das matrículas, evidenciando uma redução da população entre 6 e 14 anos no período de 2008 a 2014, e uma estabilização a partir de então no patamar de 5 milhóes de crianças e adolescentes em idade de frequentar o Ensino Fundamental (Figura 2). Se a população de 0 a 5 anos se estabilizar em torno de 3,5 milhôes de pessoas, conforme indicam as projeções demográficas, então é razoável supor que as matrículas nos Anos Iniciais do Ensino Fundamental também se estabilizem nesse patamar.

É importante notar que a queda da fecundidade (fenômeno demográfico que reduz o número absoluto e a proporção de crianças no conjunto da população) afeta cada faixa etária em um período (na população de 0 a 5 anos, ocorreu uma queda entre 2000 e 2010; na população de 6 a 14 anos, de 2009 a 2015; e assim sucessivamente, conforme apresentando na Figura 2), demonstrando que o fenômeno tem uma reduçáo acentuada em certo período e depois alcança uma estabilidade.

No caso das matrículas dos Anos Finais do Ensino Fundamental, nota-se uma tendência de redução no volume total de matrículas no período de 2000 a 2014 (tendência que se acentua a partir de 2012), que em parte pode ser relacionada ao mo-

\section{Figura 2}

Evolução da população de 0 a 14 anos, por coorte, no Estado de São Paulo, 2000-2020.

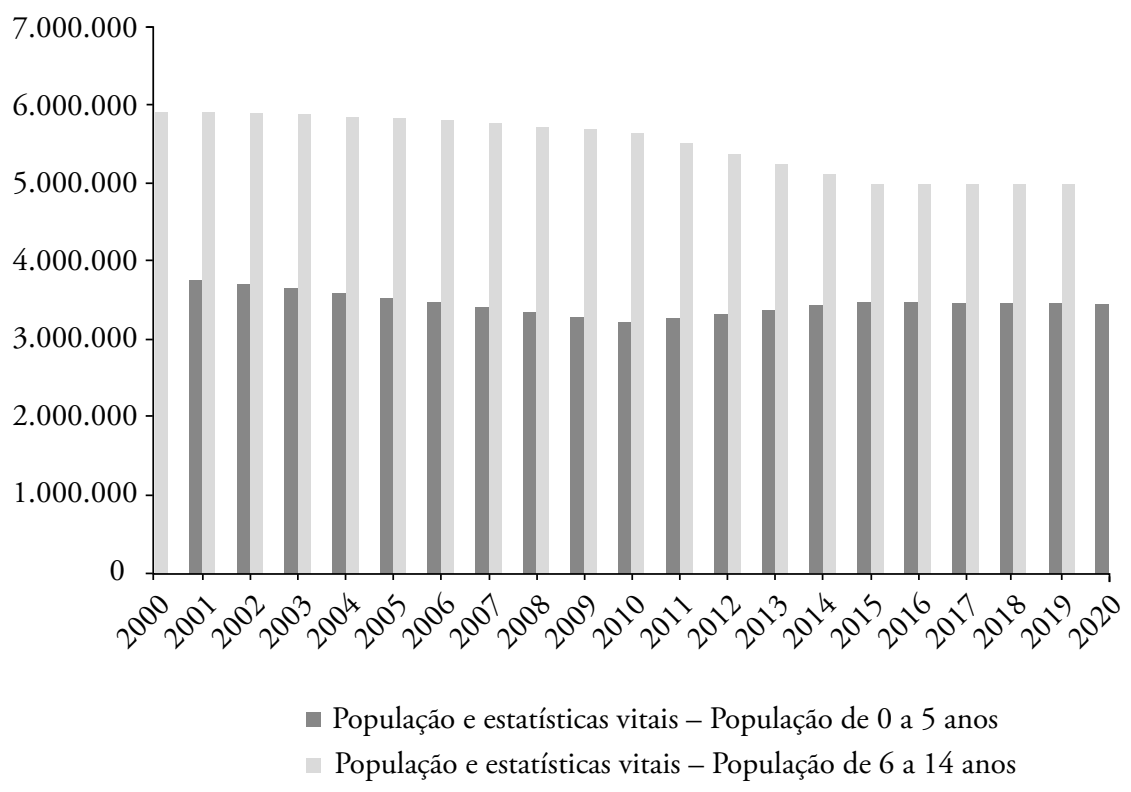

Fonte: Fundação Seade. 
vimento demográfico, mas não apenas a ele, afetando especialmente a rede estadual, que diminui sua participação relativa na oferta total de vagas nessa etapa (Figura 3).

Na população de 11 a 14 anos, a tendência foi de decréscimo do número total de adolescentes a partir de 2010, o que pode repercutir na demanda futura por vagas nos Anos Finais do Ensino Fundamental se houver uma regularização do fluxo escolar. $\mathrm{Na}$ atualidade, esse impacto não é táo significativo devido ao elevado contingente de estudantes que frequentam essa etapa do ensino com defasagem na relação idade-série, em virtude de reprovações e interrupçóes nos estudos, o que explica que a taxa bruta de matrícula exceda os $100 \%$.

O efeito da mudança demográfica sobre a demanda pelo Ensino Médio só se fez sentir a partir de 2015, quando as estimativas indicaram tendência à redução no contingente de jovens de 15 a 17 anos. Esse efeito depende, ainda, da regularização do fluxo escolar (uma vez que a taxa de escolarização líquida no Ensino Médio em 2014 situava-se em 75,8\% no Estado de Sáo Paulo, segundo a PNAD) e da

\section{Figura 3}

Evolução da matrícula nos Anos Finais do Ensino Fundamental, por dependência administrativa, no Estado de Sáo Paulo, 2000-2014.

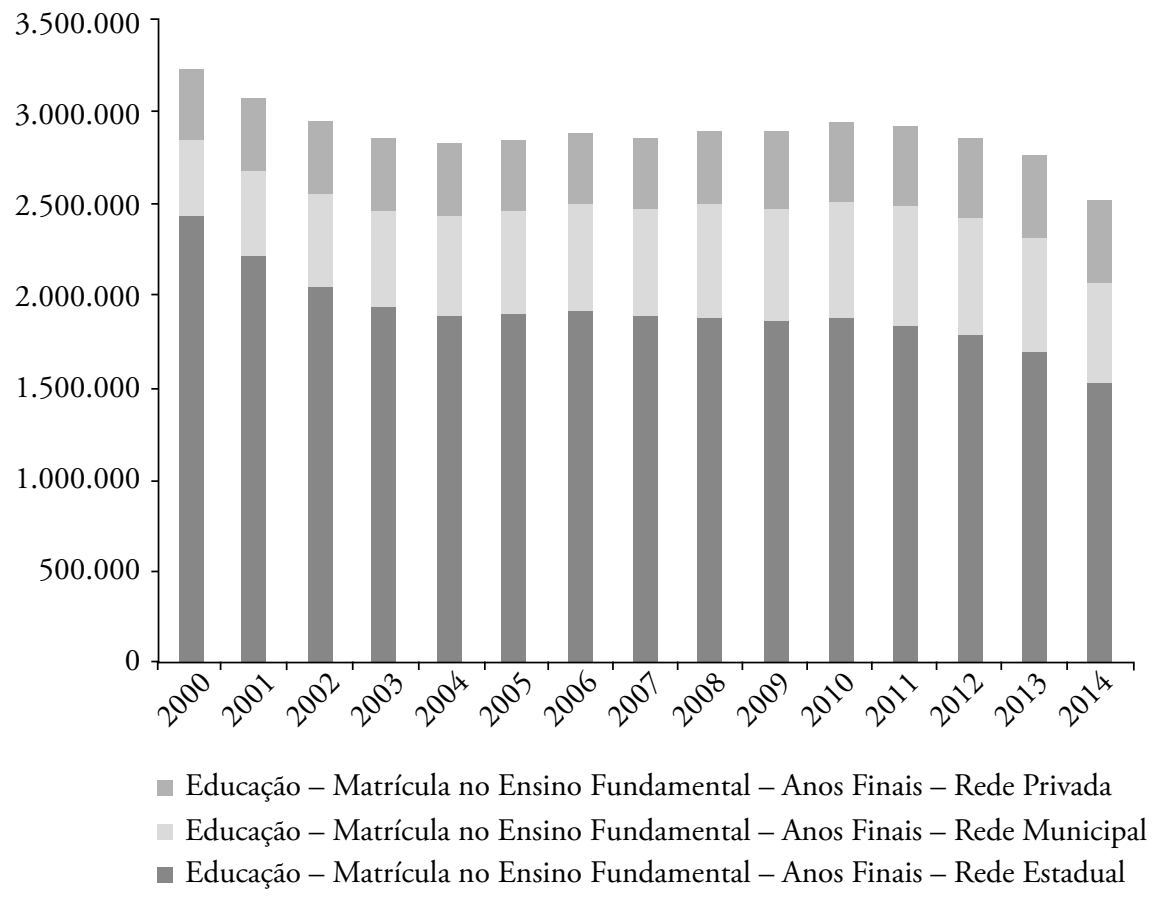

Fonte: Inep, Censo Escolar e Fundação Seade. 
capacidade de o sistema educativo atrair de volta à escola o numeroso contingente que abandonou os estudos antes de concluir a Educação Básica.

Diferentemente do que ocorreu no Ensino Fundamental, as matrículas no Ensino Médio no período de 2000 a 2014 apresentam movimentos de crescimento e queda distintos dos movimentos demográficos; por exemplo, enquanto a tendência demográfica da população de 15 a 17 anos é de estabilidade entre 2009 e 2014 (Figura 4), verifica-se aumento as matrículas no Ensino Médio desde 2009 (Figura 5), provavelmente relacionado à condição socioeconômica dos jovens e de suas famílias.

Segundo o site Portal Brasil (BRASIL, 2015),

a dinâmica da população economicamente ativa [PEA] de 16 a 24 anos nos últimos dez anos sugere que os jovens têm aumentado a participaçáo no mercado de trabalho nos períodos de desaceleração econômica, numa tentativa de recompor o rendimento familiar. Mas [...] isso não necessariamente significa ocupação, pois entre 2013 e 2014 houve um crescimento da PEA de 16 a 24 anos em 2,7\%, mas [...] a taxa de desocupaçáo neste grupo saltou de $14,8 \%$ para $16,6 \%$.

\section{Figura 4}

Evolução da população de 11 a 17 anos, por coorte, no Estado de São Paulo, 2000-2020

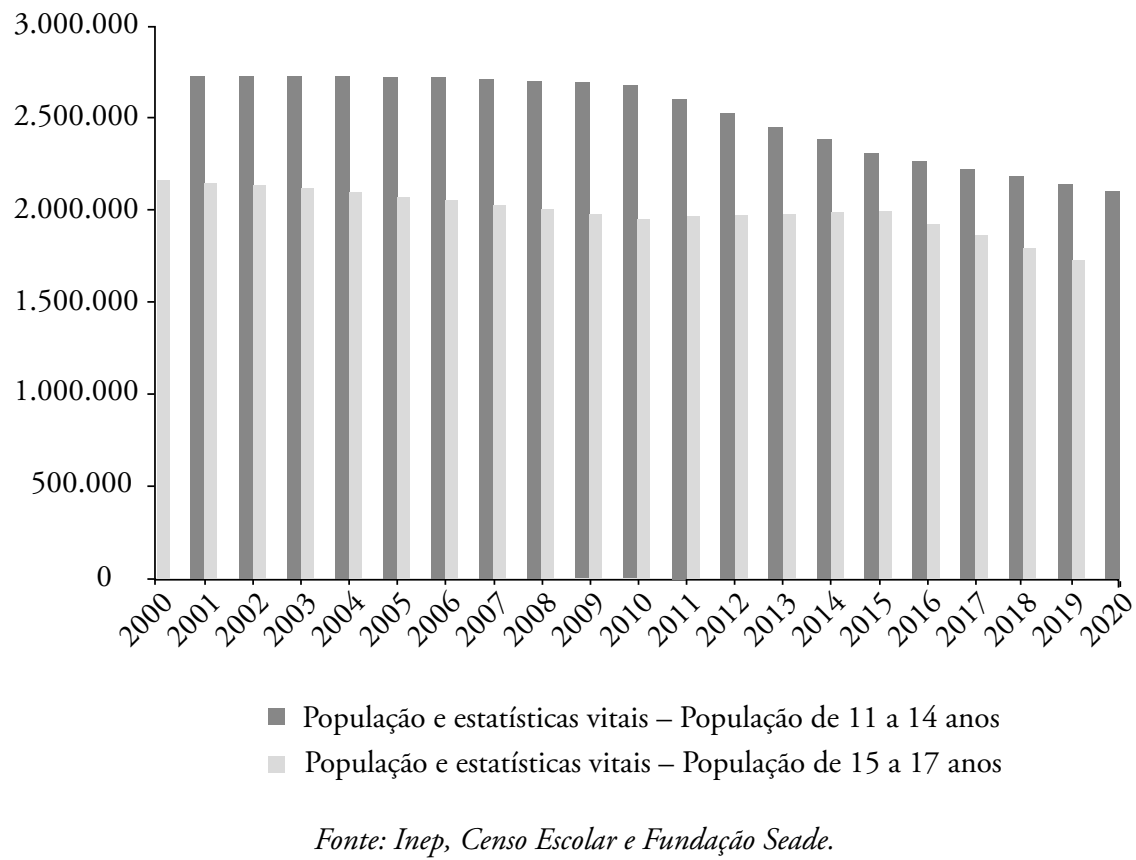


Estudos recentes confirmam essa hipótese, indicando que "a piora do emprego e da renda das famílias num cenário de estreitamento das políticas públicas e da proteção social tende a impulsionar de forma mais intensa a procura de emprego por parte dos jovens brasileiros" (SANTOS \& GIMENEZ, 2015, p. 165), e que "o segmento juvenil, que apresenta uma das mais elevadas taxas de desemprego, deve ser um dos segmentos mais afetados pela continuidade da atual crise econômica" (Ibid., p. 159).

A Figura 6 mostra que 449 mil adolescentes de 15 a 17 anos, segundo a PNAD 2014, estavam ocupados na semana de referência da pesquisa. Quando considerada a faixa dos 15 aos 19 anos, esse volume saltou para 1,196 milhão de jovens e adolescentes. A difícil conciliação entre trabalho e frequência à escola é um dos fatores que explicam as elevadas taxas de abandono do Ensino Médio e da EJA. No caso desta, a situação do atendimento é dramática, seja pela baixa cobertura, seja pela acelerada e persistente redução das matrículas registrada desde 2006, que atinge todas as redes e etapas do ensino básico, sendo mais acentuada na rede estadual (Figuras 7 e 8 ).

\section{Figura 5}

Evolução das matrículas no Ensino Médio, por dependência administrativa, no Estado de São Paulo, 2000-2014.

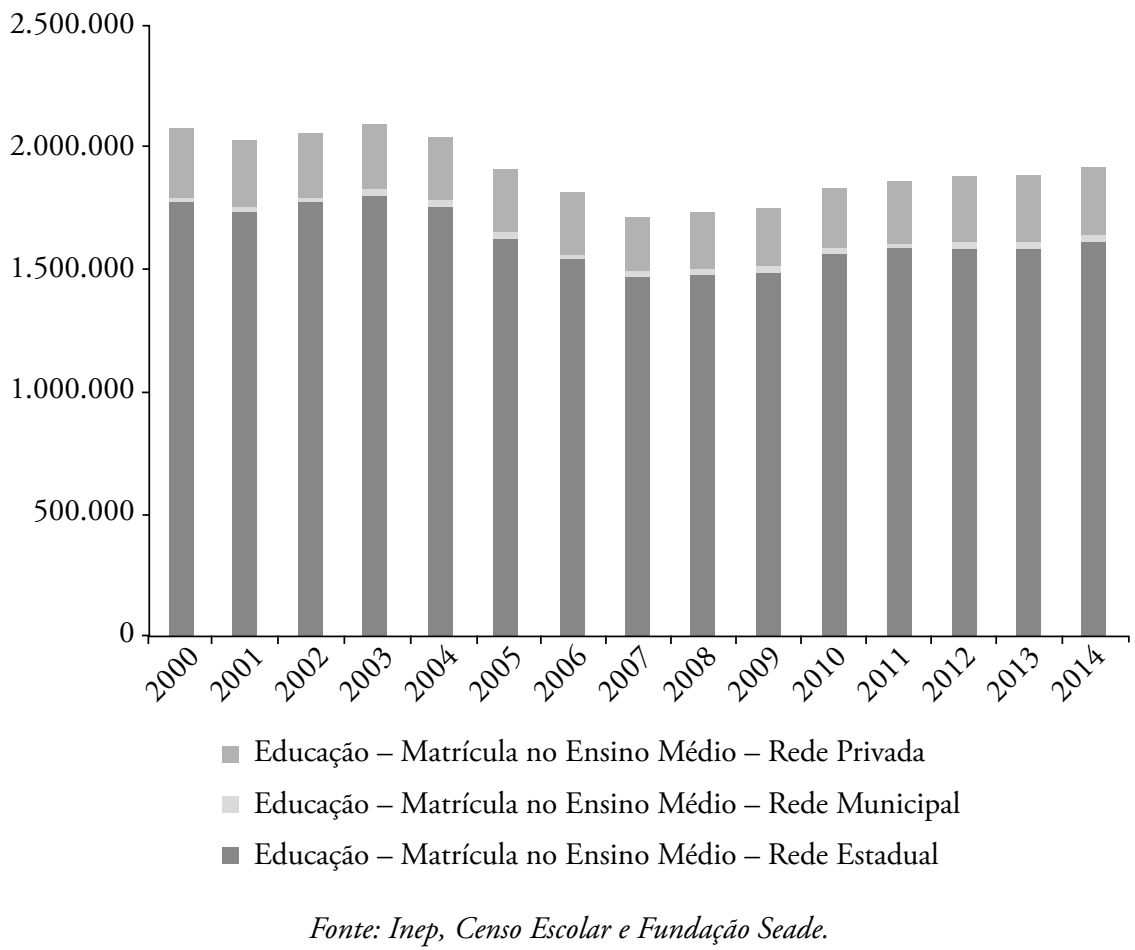


Apesar de a taxa de analfabetismo absoluto em âmbito estadual tender ao declínio e situar-se abaixo da média nacional (3,7\% em 2013), a escolaridade média da populaçáo paulista é baixa - 9,63 anos de estudo na média da população entre 15 e 64 anos, segundo a Seade (2016). De acordo com o Censo Demográfico de 2010 (IBGE, 2011), dos mais de 32 milhóes de paulistas com 15 anos ou mais, $37 \%$ não haviam terminado o Ensino Fundamental; e, dentre as pessoas com 18 anos ou mais (que totalizavam, em 2010, quase 19 milhóes em todo o Estado), mais de 5 milhões não haviam concluído o Ensino Médio. Portanto, a demanda potencial por escolarizaçâo básica de jovens e adultos no Estado somava, naquele ano, quase 17 milhóes de paulistas, e a cobertura escolar estimada por Di Pierro (2014, p. 50) era de menos de 10\%.

Essas são algumas das razóes que nos levam a questionar o planejamento da oferta de classes que considera apenas o movimento do volume de matrículas, uma vez que as dimensóes da demanda dependem de diversos fatores de natureza demográfica, socioeconômica e relacionados à gestão da educação; e, como já demonstrado nos dados da projeçáo populacional, apesar da onda esperada de queda do volume da população infantojuvenil paulista, a tendência, pelo menos até 2020, ainda será de estabilidade (Figura 9).

\section{Figura 6}

Evolução do número de crianças e adolescentes ocupados, por grupos de idade, no Estado de São Paulo, 2002-2014.

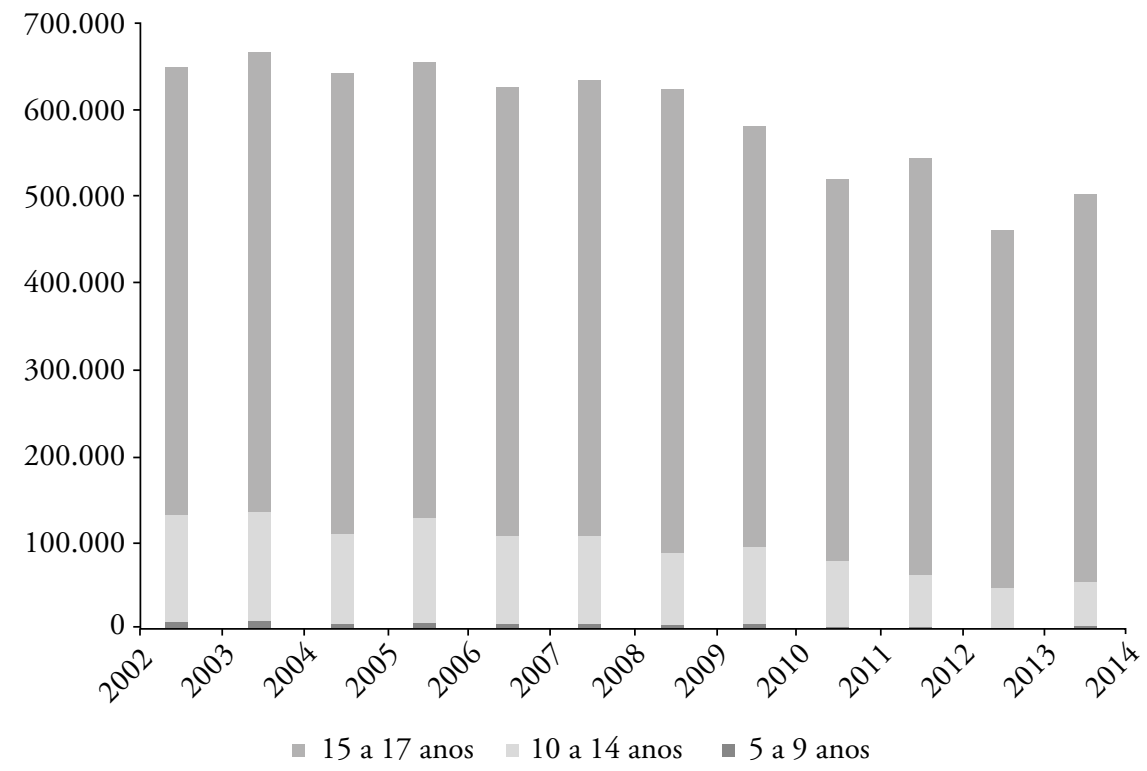

Fonte: IBGE. PNAD, 2002-2014. 
Como sugerem os dados das diferentes etapas e modalidades da educação básica paulista (Ensino Fundamental, Ensino Médio e EJA), por meio dos volumes de matrículas e das tendências demográficas dos grupos etários correspondentes, não há como afirmar, como quer crer a medida governamental da reorganização, uma necessidade premente de reduzir a oferta de unidades escolares em decorrência de uma redução da fecundidade.

Para caracterizar a demanda social por ensino, o planejamento da oferta de vagas na rede deve considerar não apenas a evolução das matrículas, uma vez que a mobilidade intra e inter-redes, o fluxo escolar e as condiçóes socioeconômicas interferem diretamente sobre o fenômeno. Além disso, deve-se considerar as condiçóes de atendimento dessa demanda, como, por exemplo, a relação de alunos por classe, como veremos nas seçôes subsequentes.

\section{Figura 7}

Evolução das matrículas no Ensino Fundamental, na modalidade EJA, por dependência administrativa, no Estado de Sáo Paulo, 2007-2014.

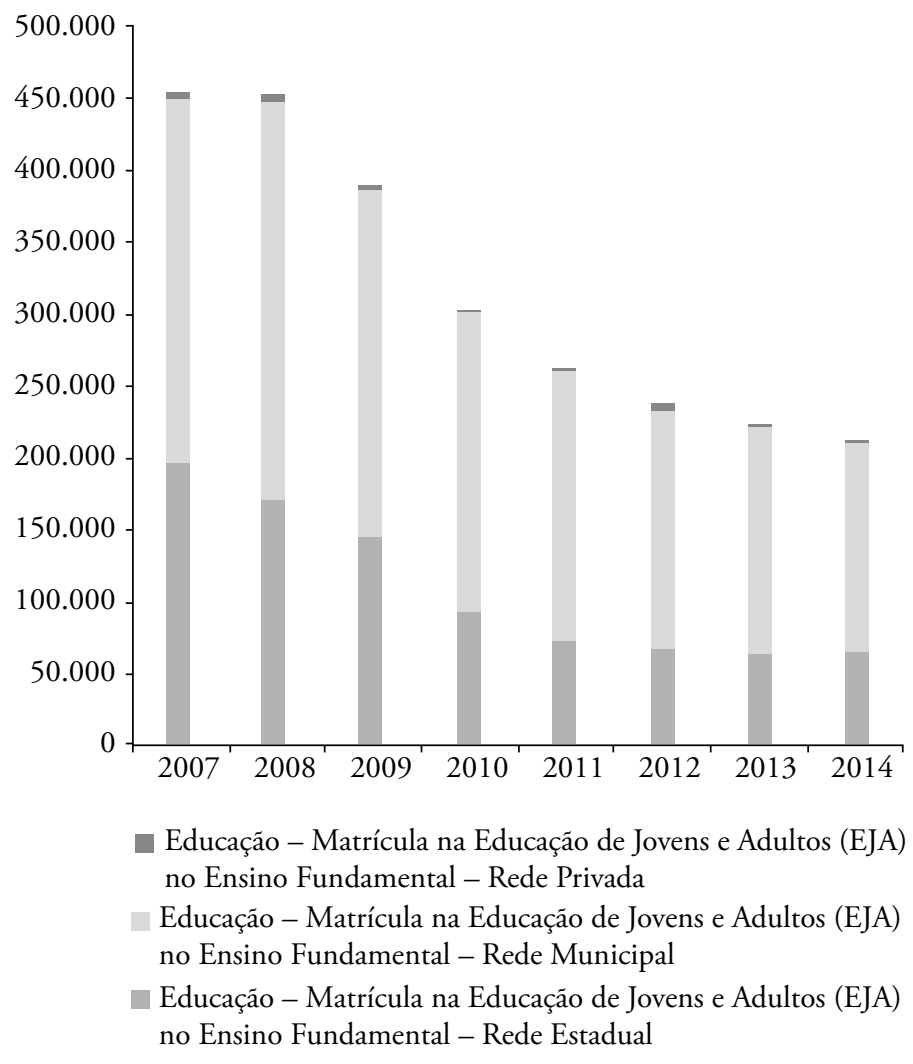

Fonte: Inep, Censo Escolar e Fundação Seade. 


\section{Estaria em curso uma reorganização escolar "silenciosa"?}

Suspensa a reorganizaçáo escolar por pressão dos estudantes e da opinião pública, e substituído o comando da pasta da Educação, ficou a expectativa de qual seria o redirecionamento da política da SEE-SP com respeito ao atendimento da demanda escolar. Tal expectativa se justifica também pela vigência da Emenda Constitucional n 59 (BRASIL, 2009) - que torna obrigatório, em 2016, o ensino dos 4 aos 17 anos - , bem como pela conjuntura de recessão econômica, que induz as famílias afetadas pelo desemprego a transferirem matrículas das escolas privadas para o ensino público gratuito.

O primeiro indício de resposta a essa questão surgiu no início de 2016, com a publicação da Resolução que normatiza os procedimentos de matrícula na

\section{Figura 8}

Evolução das matrículas no Ensino Médio, na modalidade EJA, por dependência administrativa, no Estado de São Paulo, 2007-2014.

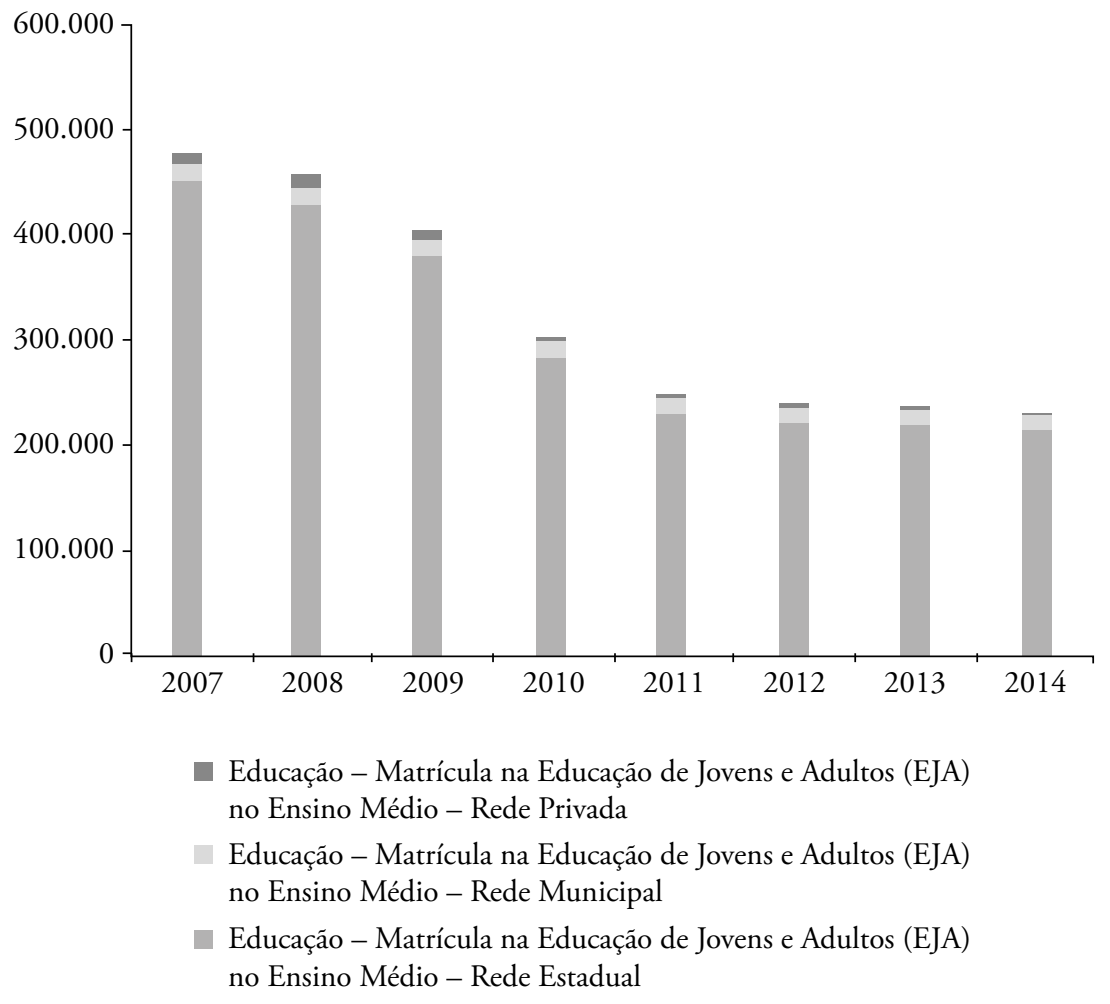

Fonte: Inep, Censo Escolar e Fundação Seade. 
rede estadual de ensino ${ }^{8}$. A Resoluçáo autorizou que, sob circunstâncias excepcionais devidamente justificadas, pudessem ser formadas turmas que excedessem em até $10 \%$ o número máximo de 30 alunos nas classes dos Anos Iniciais do Ensino Fundamental, 35 alunos nas classes dos Anos Finais, 40 alunos nas classes do Ensino Médio e 45 alunos nas classes da EJA. A norma surpreendeu não só por contrariar acordo feito com o professorado ${ }^{9}$ e referenciais nacionais de qualidade educacional ${ }^{10}$, mas também por ir na contramão da tendência observada nos anos anteriores de progressiva redução do número médio de alunos por classe na rede estadual de ensino.

Nos meses subsequentes, a imprensa repercutiu denúncias do sindicato docente sobre o fechamento de classes, ciclos e modalidades, transferências de alunos e redução do quadro de funcionários, o que poderia configurar descumprimento da liminar que determinou a suspensão da reorganização escolar. Instada pela Justiça a prestar esclarecimentos ${ }^{11}$, a Secretaria limitou-se a naturalizar tais procedimentos como ajustes pontuais e rotinas administrativas de uma rede enorme e complexa, sem maior repercussão no atendimento à demanda escolar.

\section{Figura 9}

Evolução e projeção da populaçáo infantojuvenil, no Estado de São Paulo, 2000-2020.

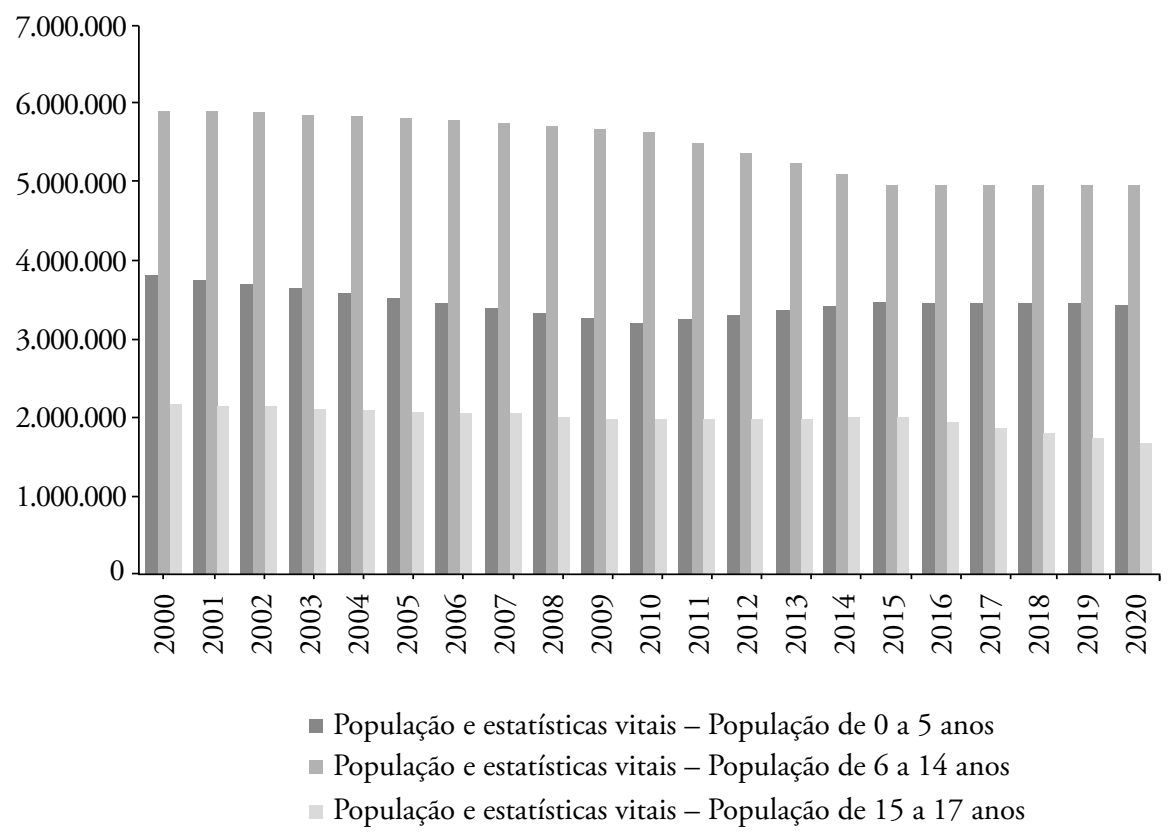

Fonte: Fundação Seade. 
Quanto à superlotação de classes, a SEE-SP informou que apenas 0,5\% das classes situadas nos extremos Sul e Leste da Capital, em Carapicuíba, Diadema, Suzano, Sáo José dos Campos e Campinas teriam sido afetadas pela condiçáo de excepcionalidade prevista na Resolução ${ }^{12}$.

No intento de avaliar a dimensão e captar o sentido da gestão recente da demanda escolar na extensa rede estadual de ensino paulista, procedemos ao estudo comparativo das matrículas, das classes (atentando à sua abertura ou fechamento), bem como do número de alunos por classe. Entretanto, como o governo estadual de São Paulo não publiciza seus dados de cadastro referentes ao ano corrente, a necessidade de análise "em tempo real" das políticas educacionais estaduais levou-nos a solicitar os dados do Cadastro de Escolas da rede estadual paulista referentes aos meses de maio de 2015 e 2016 (mês-referência para a consolidação dos dados do Censo Escolar de cada ano) via Lei n ${ }^{\circ} 12.527 / 2011$ (BRASIL, 2011) de Acesso à Informação. Os cadastros assim obtidos serviram como fontes para os dados de todos os gráficos e tabelas doravante apresentados.

Diferentemente do que poderíamos esperar se acreditássemos que a evolução de matrículas acompanha direta e exclusivamente a dinâmica populacional, constatamos que entre 2015 e 2016 não houve diminuição da demanda escolar, mas um crescimento de $0,7 \%$, uma vez que a retração de matrículas no Ensino Fundamental (especialmente nos Anos Finais) foi compensada pelo crescimento do alunado do Ensino Médio e da EJA (Tabela 1).

A partir dessa constatação, analisamos as formas de atendimento a essa demanda, verificando - para cada unidade escolar da rede e em cada ano escolar específico - a situação de abertura e fechamento de classes e de número de alunos por turma ${ }^{13}$, tratando estatisticamente esses dados, que passamos a expor.

\section{Tabela 1}

Número de matrículas e classes, ensino presencial - Rede estadual paulista, 2015-2016.

\begin{tabular}{l|c|c|c|c|c|c}
\hline \multirow{2}{*}{$\begin{array}{l}\text { Etapa/modalidade de } \\
\text { ensino }\end{array}$} & \multicolumn{3}{|c|}{ Alunos } & \multicolumn{3}{c}{ Classes } \\
\cline { 2 - 7 } & $\mathbf{2 0 1 5}$ & $\mathbf{2 0 1 6}$ & Variaçáo & $\mathbf{2 0 1 5}$ & $\mathbf{2 0 1 6}$ & Variaçáo \\
\hline $\begin{array}{l}\text { Ensino Fundamental - } \\
\text { Anos Iniciais }\end{array}$ & 635.444 & 626.797 & -8.647 & 23.229 & 23.105 & -124 \\
\hline $\begin{array}{l}\text { Ensino Fundamental - } \\
\text { Anos Finais }\end{array}$ & 1.386 .309 & 1.355 .276 & -31.033 & 45.783 & 43.953 & -1.830 \\
\hline Ensino Médio & 1.468 .598 & 1.506 .942 & 38.344 & 45.147 & 44.697 & -450 \\
\hline $\begin{array}{l}\text { Educaçáo de Jovens e } \\
\text { Adultos }\end{array}$ & 163.595 & 189.364 & 25.769 & 5.041 & 5.287 & 246 \\
\hline Total & 3.653 .946 & 3.678 .379 & 24.433 & 119.200 & 117.042 & -2.158 \\
\hline
\end{tabular}




\section{Lotação de classes}

Um primeiro aspecto da análise trata da situação de lotação das classes na rede estadual paulista. Independentemente de qualquer processo de reorganização escolar, o recrudescimento da lotação de classes constitui, por si só, indício de precarização das condições de trabalho pedagógico nas escolas e de ameaça à fruição do direito à educação pública de qualidade.

O uso de médias não é o recurso estatístico adequado para saber se há classes - e quantas há - acima dos limites estabelecidos pela Resolução SE nº 2/2016 (SÃO PAULO, 2016), pois é sabido haver uma dispersão do número de alunos por classe em torno de seus valores médios; isto é, há um número significativo de turmas com poucos alunos (classes vinculadas a escolas rurais e indígenas, por exemplo) e um número igualmente significativo de turmas em situação oposta. Assim, as médias de um conjunto tão heterogêneo de unidades escolares não representam a realidade da rede de forma adequada. Uma metodologia rigorosa de análise deverá levar necessariamente em conta as distribuiçóes do número de turmas em termos dos números de alunos por classe, comparando diferentes medidas estatísticas e analisando a dispersão dos valores.

$\mathrm{Na}$ Tabela 2 e nas Figuras 10, 11, 12, 13 e 14, podemos notar uma diferença significativa entre as médias de alunos por classe em cada modalidade e as respectivas modas ${ }^{14}$. Estas, em cada modalidade, são significativamente maiores do que aquelas, indicando uma grande concentração de classes com mais alunos do que a média. A forma dos gráficos não é simétrica, e eles apresentam máximos deslocados para a direita, que indicam uma "preferência" por classes com muitos alunos, tendência que se mostra intensificada nas curvas relativas a 2016.

\section{Tabela 2}

Médias e modas dos números de alunos por classe - Rede estadual paulista, 2015-2016.

\begin{tabular}{l|c|c|c|c}
\hline \multirow{2}{*}{ Etapa } & \multicolumn{2}{|c|}{$\mathbf{2 0 1 5}$} & \multicolumn{2}{c}{ 2016 } \\
\cline { 2 - 5 } & Média & Moda & Média & Moda \\
\hline EF-AI & 27,3 & 30 & 27,1 & 30 \\
\hline EF-AF & 30,2 & 34 & 30,8 & 35 \\
\hline EM & 32,6 & 35 & 33,7 & 37 \\
\hline EJA (EF-AF) & 27,1 & indefinido & 29,7 & indefinido \\
\hline EJA (EM) & 33,6 & 41 & 36,6 & 45 \\
\hline
\end{tabular}

EF: Ensino Fundamental; AI: Anos Iniciais; AF: Anos Finais; EM: Ensino Médio; EJA: Educação de Jovens e Adultos. 


\section{Figura 10}

Frequência de classes em função do número de alunos por classe nos Anos Iniciais do Ensino Fundamental - Rede estadual paulista, 2015-2016.

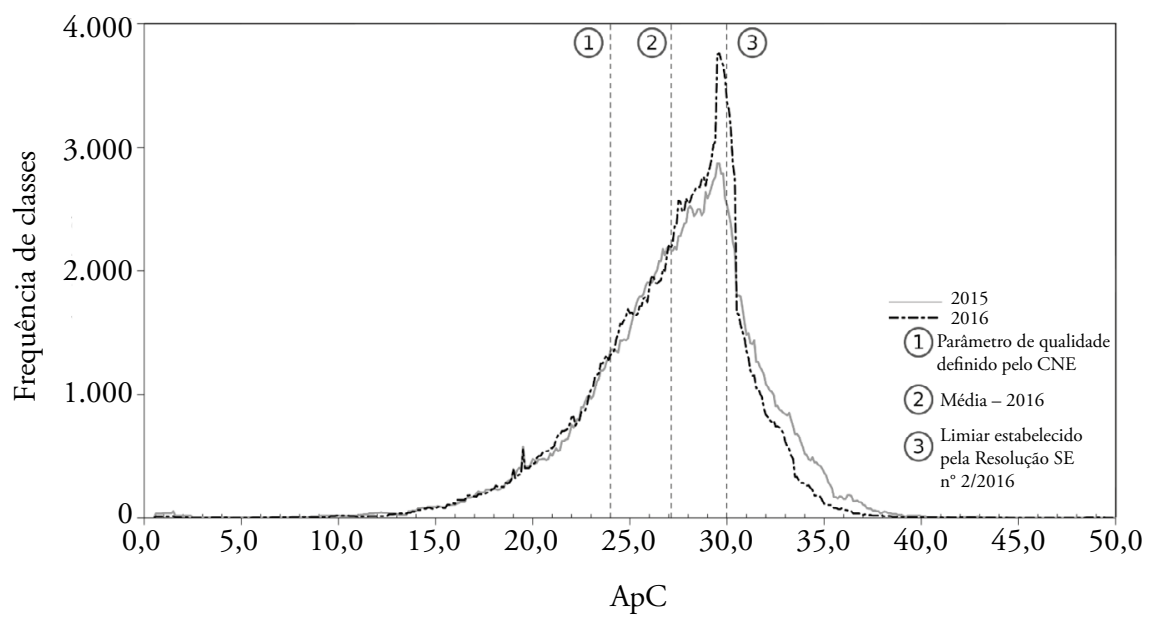

CNE: Conselho Nacional de Educação; ApC: alunos por classe.

\section{Figura 11}

Frequência de classes em função do número de alunos por classe nos Anos Finais do Ensino Fundamental - Rede estadual paulista, 2015-2016.

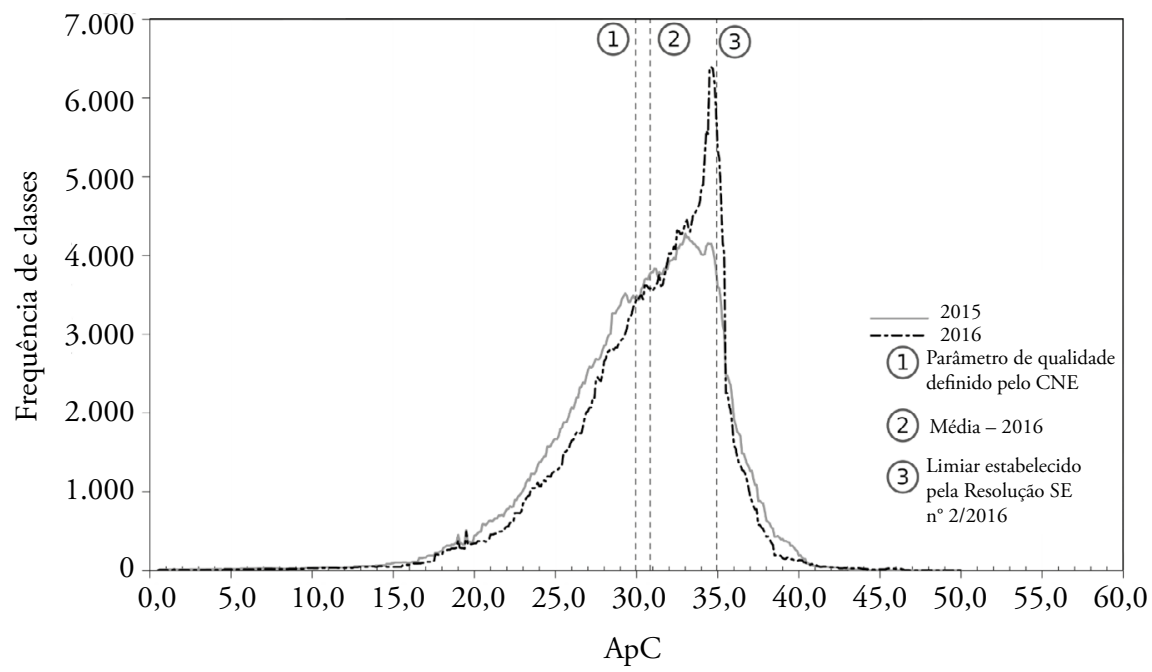

CNE: Conselho Nacional de Educação; ApC: alunos por classe. 
Nota-se que, em 2016, à exceção do Ensino Médio, nas demais etapas e na modalidade EJA a moda de alunos por classe é numericamente igual aos referenciais estabelecidos pela Resolução SE n 2/2016 (SÃO PAULO, 2016) e que, na transição 2015-2016, o valor da moda de alunos por classe aumentou ou permaneceu inalterado em todas as etapas e modalidades consideradas. Particularmente intenso foi o aumento da moda de alunos por classe para a modalidade EJA no Ensino Médio, que saltou de 41 para 45 alunos por classe, indicando que a elevação dos referenciais para essa modalidade na Resolução teve repercussão imediata na gestão da demanda escolar.

No Ensino Médio, o aumento da moda foi menor (de 35 para 37 alunos por classe), mas podemos observar na Figura 12 um incremento significativo de classes com 40 alunos (variando de 1.800 para 3.200 classes nessa condição; um aumento de $78 \%$ entre 2015 e 2016). No Ensino Fundamental, notamos igualmente um aumento bastante significativo das classes com número de alunos correspondente ao limiar do módulo estabelecido pela Resolução SE nº 2/2016 (SÃO PAULO, 2016), como demonstram as Figuras 10 e 11. Em particular, nos Anos Finais do Ensino Fundamental, ocorreu um salto de cerca de 4.200 classes com 35 alunos em 2015 para 6.400 classes nessa condição em 2016 (um aumento de 52\%).

Logo, é legítimo supor que a gestão da demanda de matrículas na rede estadual paulista se orientou por uma diretriz que induziu à formação do maior

\section{Figura 12}

Frequência de classes em função do número de alunos por classe no Ensino Médio - Rede estadual paulista, 2015-2016.

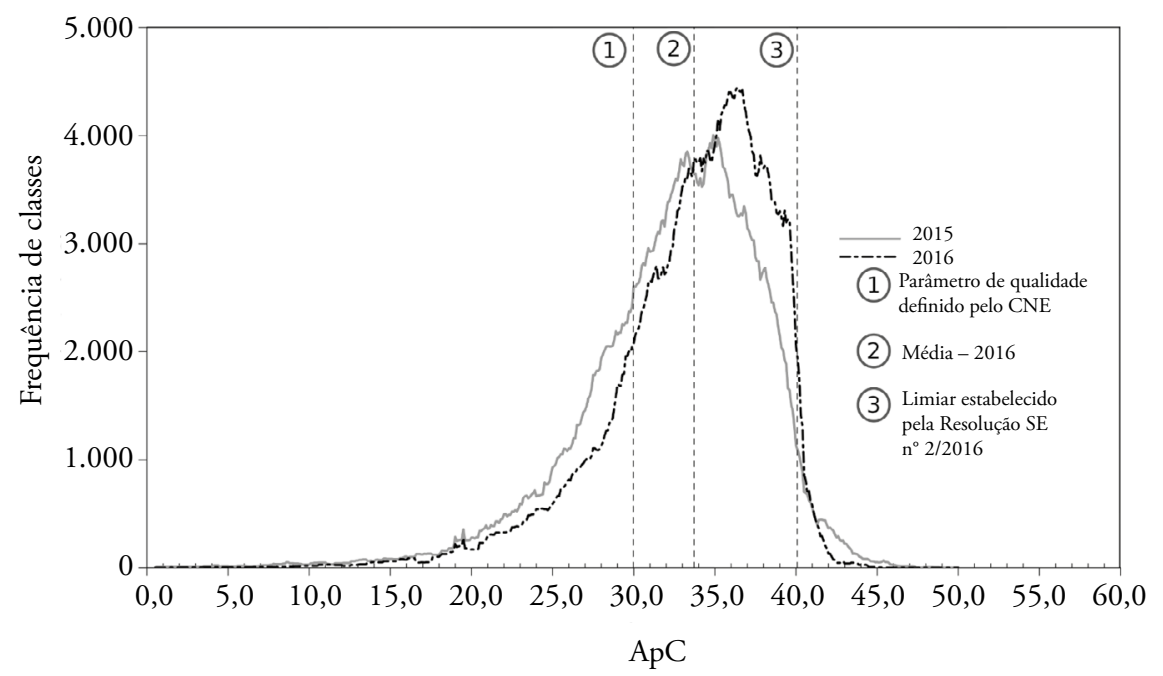

CNE: Conselho Nacional de Educaşão; ApC: alunos por classe. 
número possível de turmas no teto legalmente admitido de alunos por classe. Poderíamos, então, nos perguntar se essa diretriz também gera, colateralmente, um número significativo de classes com número de alunos além do limite. Com efeito, a Tabela 3 evidencia que $14 \%$ dos alunos da rede estadual de Sáo Paulo, em 2016, se encontram em classes com lotaçáo acima do módulo definido pela Resolução SE n 2/2016 (SÃO PAULO, 2016), proporção bem superior à declarada pela SEE-SP à Justiça e que não pode ser caracterizada como "excepcionalidade".

Embora a proporção de classes lotadas seja alta em todas as etapas e modalidades ${ }^{15}$, chama atenção que cerca de $30 \%$ das turmas dos Anos Iniciais do Ensino Fundamental se encontrem nessa condição. É possível notar um pequeno recuo na proporção de classes superlotadas no ensino regular entre 2015 e 2016, em contraposição à multiplicação das turmas da EJA nessa situação, o que torna evidente a degradação das condiçóes de ensino e aprendizagem nessa modalidade, legitimada pela publicação da Resolução SE nº 2/2016 (SÃO PAULO, 2016).

Em síntese, verifica-se que de 2015 a 2016 houve um discreto crescimento no volume de matrículas da rede estadual paulista, e uma variação significativa na distribuição de alunos por classe, que levou ao aumento da quantidade de classes com

\section{Figura 13}

Frequência de classes em função do número de alunos por classe na Educação de Jovens e Adultos, Ensino Fundamental - Rede estadual paulista, 2015-2016.

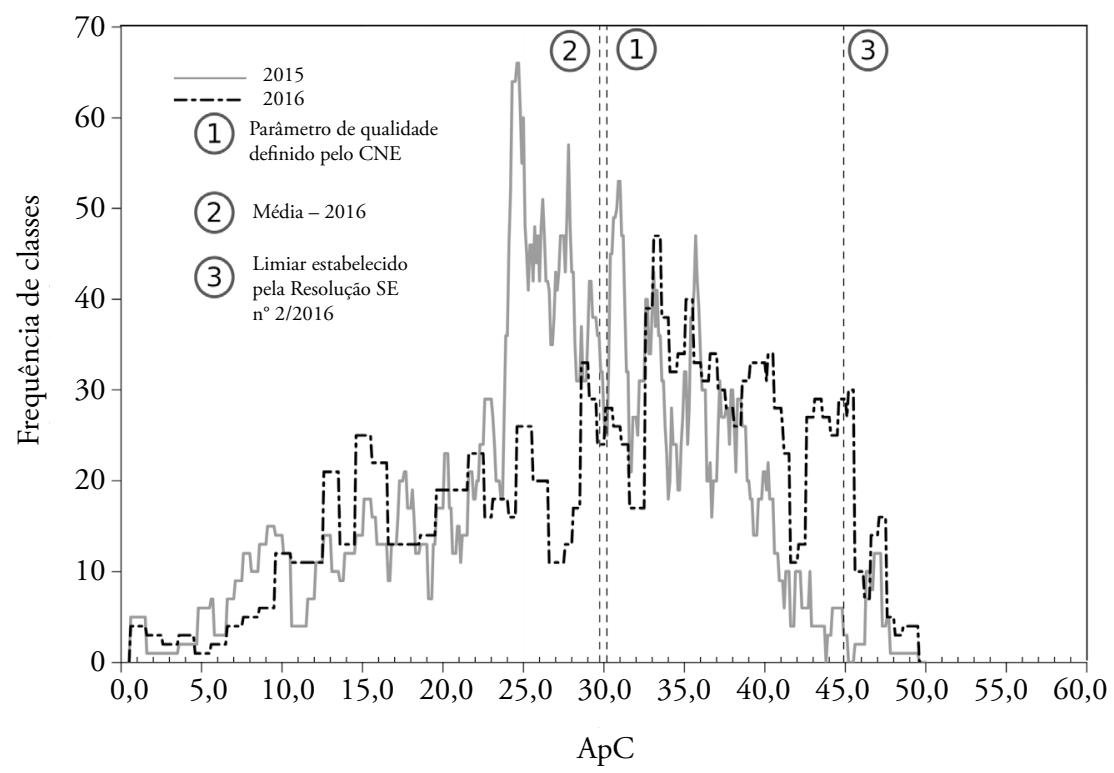

CNE: Conselho Nacional de Educação; ApC: alunos por classe. 


\section{Figura 14}

Frequência de classes em função do número de alunos por classe na Educação de Jovens e Adultos, Ensino Médio - Rede estadual paulista, 2015-2016.

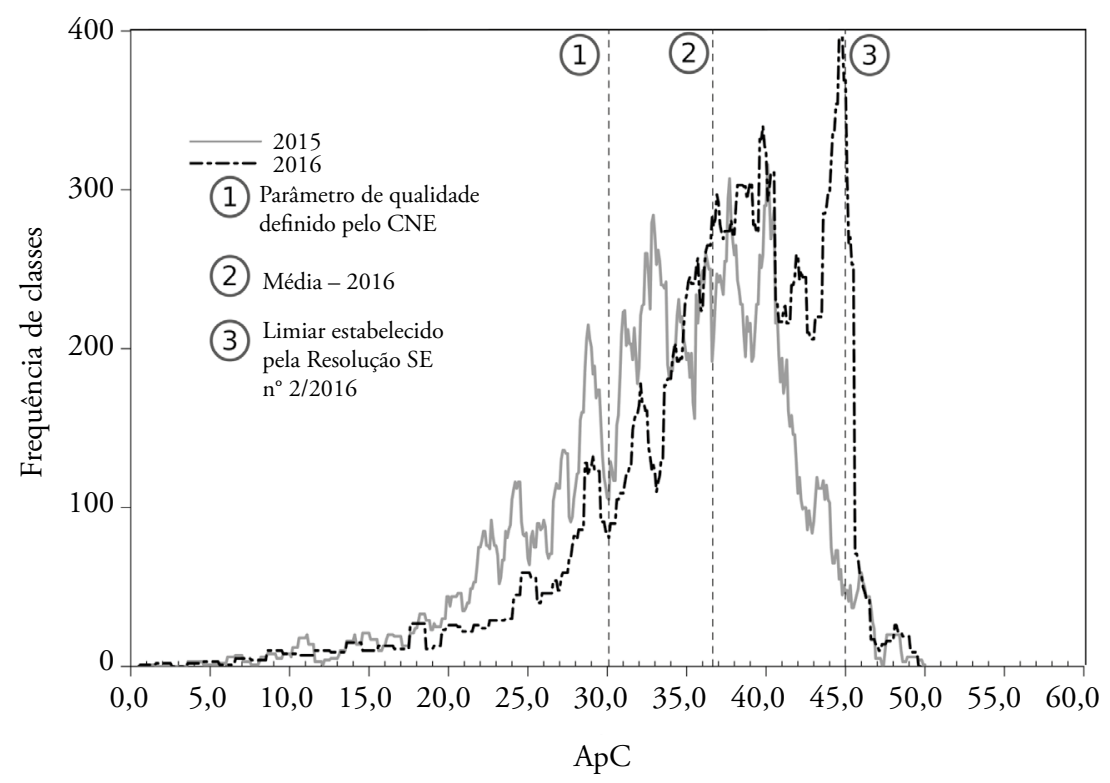

CNE: Conselho Nacional de Educação; ApC: alunos por classe.

\section{Tabela 3}

Número de alunos em classes com lotação acima dos referenciais estabelecidos pela Resolução SE n 2/2016 - Rede estadual paulista, 2015-2016.

\begin{tabular}{l|c|c|c|c|c}
\hline \multirow{2}{*}{ Etapa } & \multirow{2}{*}{$\begin{array}{c}\text { Limiar do } \\
\text { módulo }\end{array}$} & $\begin{array}{c}\text { Número de alunos } \\
\text { em classes acima do } \\
\text { limiar }\end{array}$ & $\begin{array}{c}\text { Fraçáo } \\
\text { do total } \\
(\%)\end{array}$ & $\begin{array}{c}\text { Número de alunos } \\
\text { em classes acima do } \\
\text { limiar }\end{array}$ & $\begin{array}{c}\text { Fraçáo } \\
\text { do total } \\
(\%)\end{array}$ \\
\hline EF-AI & $30 \mathrm{ApC}$ & 205.431 & 32 & 176.596 & 28 \\
\hline EF-AF & $35 \mathrm{ApC}$ & 254.199 & 18 & 249.594 & 18 \\
\hline EM & $40 \mathrm{ApC}$ & 81.997 & 6 & 72.884 & 5 \\
\hline EJA (EF-AF) & $45 \mathrm{ApC}$ & 752 & 3 & 2.767 & 11 \\
\hline EJA (EM) & $45 \mathrm{ApC}$ & 5.718 & 4 & 15.545 & 10 \\
\hline TOTAL & & 541.627 & 15 & 499.074 & 14 \\
\hline
\end{tabular}

Fonte adicional: Resolução $S E n^{\circ}$ 2/2016).

EF: Ensino Fundamental; AI: Anos Iniciais; AF: Anos Finais; EM: Ensino Médio; EJA: Educação de Jovens e Adultos; ApC: alunos por classe. 
o número máximo de alunos previsto pela Resolução SE nº 2/2016 (SÃO PAULO, 2016). Na maioria dos casos, essa ação teve como resultado um incremento do número de classes mais cheias e uma diminuição do número de classes mais vazias, sendo particularmente grave a situação da EJA e dos Anos Iniciais do Ensino Fundamental.

A variação na distribuição de alunos por classe na transição 2015-2016 com a moda da distribuição tendendo aos parâmetros definidos pela Resolução SE nº 2/2016 (SÃO PAULO, 2016) - é evidência adicional da vigência de um modo de administração pública de vertente gerencial, em que as dimensões econômico-financeira (racionalização de recursos) e institucional-administrativa (padronização da rede, publicação de atos normativos) sobrepujam a dimensão sociopolítica, enfatizada nos modelos de administração pública de caráter societal e baseados na gestáo participativa (PAULA, 2005).

\section{Fechamento de classes}

Passamos a analisar um segundo aspecto das flutuaçóes de dados na rede estadual paulista, mirando agora o fechamento de classes relacionado ao encerramento de ciclos, ponto nevrálgico do processo de reorganização escolar suspenso em 2015.

Ao prestar informações à Justiça em 2016, a SEE-SP alegou que o fechamento e a abertura de classes corresponderiam a movimentos "naturais" em uma rede escolar extensa e complexa. É verdade que em uma rede com mais de 5.000 escolas há muitas flutuações (unidades escolares são reformadas, outras inauguradas) e a demanda por matrículas - compartilhada com as redes municipais e privadas - é influenciada por múltiplos fatores. Entretanto, considerando os antecedentes, é preciso verificar se o fechamento de classes em 2016, na rede estadual paulista, seguiu algum tipo de "dinâmica natural" ou se reflete as escolhas da administração estadual para a gestão da demanda escolar.

Diante desse desafio, e face aos dados disponíveis, optamos por comparar os casos de fechamento e abertura de classes na transição 2015-2016 ocorridos no conjunto de toda a rede estadual com os ocorridos nas unidades escolares que compunham as listas divulgadas pela SEE-SP em 2015; ou seja, a lista das escolas que seriam completamente fechadas $(\mathrm{n}=94)$ e a lista das 754 escolas que se tornariam unidades de ciclo único, divididas em 3 subconjuntos: escolas que passariam a atender apenas os Anos Iniciais do Ensino Fundamental ( $\mathrm{n}=55)$, apenas os Anos Finais do Ensino Fundamental ( $n=361)$, e apenas o Ensino Médio $(n=338)$. Se a tendência de abertura e fechamento de turmas nesses subconjuntos fosse suficientemente próxima da tendência observada no conjunto da rede estadual, a tese das "flutuaçôes naturais" seria corroborada.

Para realizar essa comparação, calculamos a variação porcentual do número de classes ${ }^{16}$ para cada etapa de ensino no universo da rede estadual paulista 
e no universo dos subconjuntos que mencionamos. Os resultados, sistematizados nas Tabelas 4, 5 e 6, demonstram uma tendência muito diferente nesses subconjuntos em relação ao total da rede estadual.

Em todos os casos, vemos que o fechamento de classes nos subconjuntos investigados é muito mais intenso do que no universo da rede estadual, exceto quando o fechamento se refere à etapa planejada para essas unidades escolares no contexto da proposta de reorganização em ciclos únicos. A Tabela 4, por exemplo, que apresenta a abertura e fechamento de classes de Anos Iniciais do Ensino Fundamental, aponta uma tendência geral de fechamento dessas classes na rede toda e em todos os subconjuntos investigados, exceto no subconjunto das 55 unidades escolares que atenderiam exclusivamente os Anos Iniciais do Ensino Fundamental (em que a tendência é de abertura de classes). Tal resultado, que também é observado para as outras etapas de ensino ${ }^{17}$, está longe de ser acidental.

Em relaçáo ao subconjunto das 94 unidades escolares que seriam totalmente fechadas segundo a proposta de reorganização de 2015, nota-se nas três tabelas uma tendência de fechamento de classes nas três etapas investigadas, muito maior nesse subconjunto do que no universo da rede.

Os mesmos dados também podem ser apresentados graficamente, na forma de curvas de distribuição porcentual de abertura/fechamento de classes. A Figura 15 mostra essa distribuição para o subconjunto das 338 unidades escolares que, na proposta de reorganização apresentada em 2015, se tornariam escolas exclusivas de Ensino Médio ${ }^{18}$.

\section{Tabela 4}

Aberturas e fechamentos de classes de Anos

Iniciais do Ensino Fundamental - Rede estadual paulista, 2016.

\begin{tabular}{l|c|c|c|c|c}
\hline Subconjuntos & $\begin{array}{c}\text { Classes } \\
\text { abertas }\end{array}$ & $\begin{array}{c}\text { Classes } \\
\text { fechadas }\end{array}$ & Variaçáo & $\mathbf{\%}$ & $\begin{array}{c}\text { f entre a tendência } \\
\text { no subconjunto e no } \\
\text { total da rede (\%) }\end{array}$ \\
\hline Toda a rede (n=5.688) & 790 & 865 & -75 & $-0,3$ & - \\
\hline $\begin{array}{l}\text { Passariam a atender } \\
\text { apenas EF-AI (n=55) }\end{array}$ & $\mathbf{7 2}$ & $\mathbf{1 4}$ & $\mathbf{+ 5 8}$ & $\mathbf{+ 7 , 1}$ & $\mathbf{- 2 . 3 0 0}$ \\
\hline $\begin{array}{l}\text { Passariam a atender } \\
\text { apenas EF-AF (n=361) }\end{array}$ & 7 & 44 & -37 & $-16,7$ & 5.073 \\
\hline $\begin{array}{l}\text { Passariam a atender } \\
\text { apenas EM (n=338) }\end{array}$ & 5 & 19 & -14 & $-11,6$ & 3.475 \\
\hline Fechamento total (n=94) & 12 & 33 & -21 & $-7,2$ & 2.137 \\
\hline
\end{tabular}

EF: Ensino Fundamental; AI: Anos Iniciais; AF: Anos Finais; EM: Ensino Médio 
A leitura das curvas mostra que a tendência de abertura/fechamento de classes nesse subconjunto é de fechamento de classes de Anos Finais do Ensino Fundamental (e também de Anos Iniciais) em concomitância com a abertura de classes de Ensino Médio, o que corresponde à proposta de reorganização por ciclos apresentada para essas unidades escolares e aos dados quantitativos apresentados na Tabela 6.

A dinâmica de abertura e fechamento de classes é um fenômeno multifatorial, e para o caso particular dos subconjuntos estudados, que figuraram em listas amplamente divulgadas, não se pode descartar a hipótese de que a

\section{Tabela 5}

Aberturas e fechamentos de classes de Anos Finais do Ensino Fundamental - Rede estadual paulista, 2016.

\begin{tabular}{l|c|c|c|c|c}
\hline Subconjuntos & $\begin{array}{c}\text { Classes } \\
\text { abertas }\end{array}$ & $\begin{array}{c}\text { Classes } \\
\text { fechadas }\end{array}$ & Variaçáo & $\mathbf{\%}$ & $\begin{array}{c}\text { f entre a tendência } \\
\text { no subconjunto e no } \\
\text { total da rede (\%) }\end{array}$ \\
\hline Toda a rede (n=5.688) & 1.737 & 3.537 & -1.800 & $-3,9$ & \\
\hline $\begin{array}{l}\text { Passariam a atender } \\
\text { apenas EF-AI (n=55) }\end{array}$ & 15 & 69 & -54 & $-11,3$ & 187 \\
\hline $\begin{array}{l}\text { Passariam a atender } \\
\text { apenas EF-AF (n=361) }\end{array}$ & $\mathbf{2 4 7}$ & $\mathbf{3 1 0}$ & $\mathbf{- 6 3}$ & $\mathbf{- 1 , 3}$ & $\mathbf{- 6 6}$ \\
\hline $\begin{array}{l}\text { Passariam a atender } \\
\text { apenas EM (n=338) }\end{array}$ & 60 & 590 & -530 & $-12,1$ & 207 \\
\hline Fechamento total (n=94) & 8 & 76 & -68 & $-13,9$ & 251 \\
\hline
\end{tabular}

EF: Ensino Fundamental; AI: Anos Iniciais; AF: Anos Finais; EM: Ensino Médio.

\section{Tabela 6}

Aberturas e fechamentos de classes de Ensino Médio - Rede estadual paulista, 2016.

\begin{tabular}{l|c|c|c|c|c}
\hline Subconjuntos & $\begin{array}{c}\text { Classes } \\
\text { abertas }\end{array}$ & $\begin{array}{c}\text { Classes } \\
\text { fechadas }\end{array}$ & Variaçáo & $\mathbf{\%}$ & $\begin{array}{c}\text { f entre a tendência } \\
\text { no subconjunto e no } \\
\text { total da rede (\%) }\end{array}$ \\
\hline Toda a rede (n=5.688) & 2.097 & 2.444 & -347 & $-0,8$ & \\
\hline $\begin{array}{l}\text { Passariam a atender } \\
\text { apenas EF-AI (n=55) }\end{array}$ & 9 & 28 & -19 & $-8,4$ & 986 \\
\hline $\begin{array}{l}\text { Passariam a atender } \\
\text { apenas EF-AF (n=361) }\end{array}$ & 122 & 333 & -211 & $-5,6$ & 627 \\
\hline $\begin{array}{l}\text { Passariam a atender } \\
\text { apenas EM (n=338) }\end{array}$ & $\mathbf{3 2 4}$ & $\mathbf{1 6 2}$ & $\mathbf{+ 1 6 2}$ & $\mathbf{+ 3 , 0}$ & $\mathbf{- 4 9 0}$ \\
\hline Fechamento total (n=94) & 30 & 36 & -6 & $-1,3$ & 73 \\
\hline
\end{tabular}

EF: Ensino Fundamental; AI: Anos Iniciais; AF: Anos Finais; EM: Ensino Médio. 
própria veiculação das listas de fechamento das unidades ou ciclos tenha levado a um movimento de transferências voluntárias de matrículas para fora ou para dentro dessas unidades escolares. Ainda assim, se esse projeto náo foi levado a cabo como planejado por conta de pressôes sociais e judiciais, não se pode ignorar o fato de que as mesmas unidades escolares que constavam das listas divulgadas exibem um padrão de abertura e fechamento de classes que é compatível com o projeto suspenso.

De fato, as variaçóes porcentuais de fechamentos e aberturas de classes sáo pequenas se considerarmos o total da rede; mas as enormes diferenças porcentuais entre as tendências observadas nesse universo e nos subconjuntos demonstram claramente a intensificação da abertura e do fechamento de classes (de certas etapas) nesses subconjuntos. Isso desqualifica a tese de que as aberturas e fechamentos de classes na rede estadual paulista seguiriam uma dinâmica "natural". Embora não seja possível identificar o sentido exato da movimentaçáo escolar ocorrida na transição 2015-2016, os dados não permitem descartar a hipótese da existência de um processo de "reorganização silenciosa" na rede estadual, ecoando o que a imprensa paulista tem noticiado desde o início de 2016.

\section{Figura 15}

Distribuição de abertura/fechamento de classes para as unidades que se tornariam escolas de Ensino Médio na proposta de reorganização de 2015 - Rede estadual paulista, 2015-2016

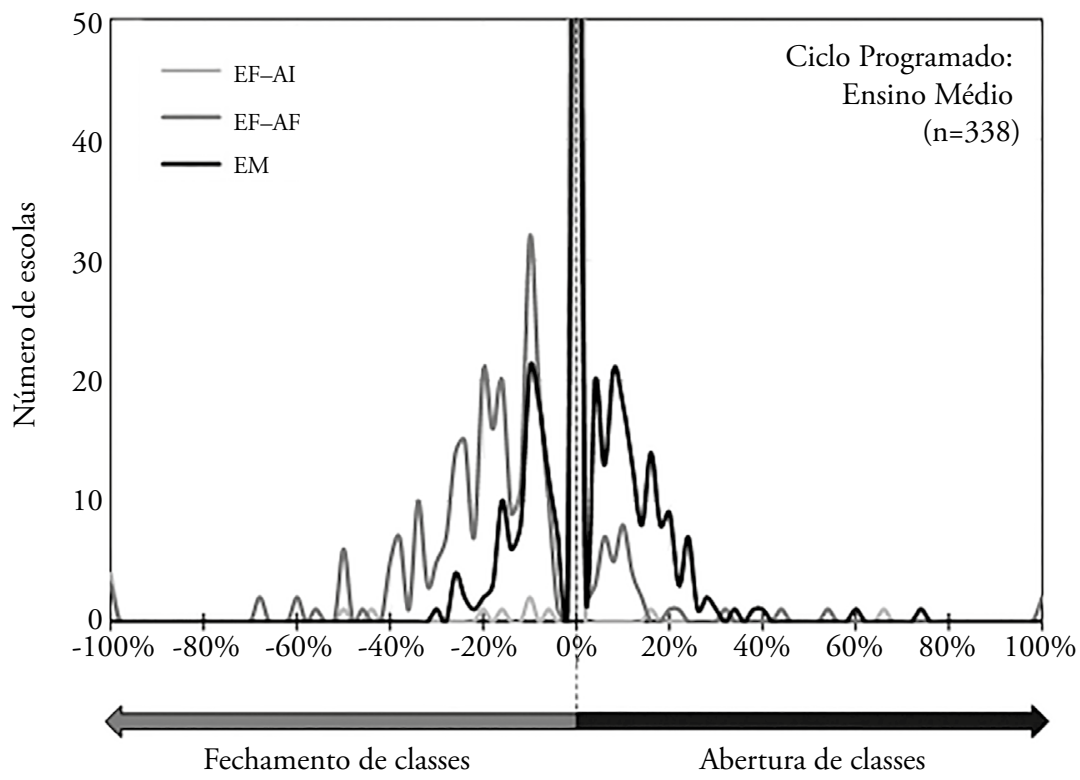




\section{Elementos para uma análise da gestão da demanda escolar na rede estadual paulista}

Quando, em fins de 2015, os estudantes paulistas ocuparam suas escolas para resistir à proposta de reorganização da rede estadual de educação básica, além da flagrante discordância entre as partes envolvidas a respeito da participação social nas decisôes governamentais e da avaliação das condiçóes de ensino e aprendizagem, estavam também em confronto diferentes perspectivas a respeito da demanda social, do direito à educação e do sentido público do ensino em instituições mantidas pelo Estado.

De certo modo, os estudantes, suas famílias e apoiadores repunham na arena pública a promessa irrealizada do projeto civilizatório da modernidade de garantia de igualdade de oportunidades na sociedade letrada e meritocrática por meio do acesso universal a uma escola pública, laica e gratuita em que os valores democráticos seriam cultivados desde a infância.

Há tempos esse projeto, que transformou a educação em direito social, vem sendo corroído por perspectivas que a submeteram à racionalidade econômica da teoria do capital humano, convertendo-a em serviço mercantilizado cujos custos podem ser contabilizados por taxas de retorno do investimento.

$\mathrm{Na}$ transição do milênio, a hegemonia do pensamento liberal-conservador em um contexto internacional de reconfiguração das forças produtivas e de redefinição do papel do Estado induziu profundas mudanças nos modos de regulação e administração estatais, legitimadas por discursos em prol do equilíbrio fiscal e da eficiência do setor público. No plano econômico, a reforma do Estado visa acomodar os interesses das corporaçóes privadas em um capitalismo financista que aumentou a produtividade do trabalho por meio do constante aprimoramento técnico nos processos de produção e que, por consequência, teve de flexibilizar as relaçôes de trabalho, fragmentar a organização sindical e gerar novas oportunidades de investimentos via privatização de ativos públicos. A administração pública, por sua vez, passou a assimilar conceitos e práticas da gestão empresarial (como o protagonismo das lideranças, a flexibilização, o aperfeiçoamento dos controles com vistas aos incentivos pela produtividade, à prestação de contas e à responsabilização), e a ressignificar outros que lhe eram próprios (como os de autonomia e profissionalização).

No Brasil, o novo modelo de gestão pública decorrente dessas reformas administrativas de cunho gerencial e privatista alcançou os modos de regulação das políticas sociais ainda durante o processo de redemocratização, logo estabelecendo um conflito com a concepção de seguridade social da Constituição de 1988. E, dada a configuração federativa do país, as pressóes por descentralização dos serviços sociais colocaram os entes federados em constantes pugnas por desresponsabilização, transferência de encargos e disputa por recursos - tendo as políticas de municipalização e de fundos de financiamento do ensino como bons exemplos. 
Ao longo dos últimos 30 anos, as reformas educativas conduzidas por esse novo modelo de gestão produziram sucessivos distanciamentos do projeto de ensino público, gratuito e laico. Dentre as tendências dessas reformas bem documentadas por estudos empíricos e ensaios teóricos, a literatura nacional, em diálogo com os estudos comparados internacionais, destaca: a difusão do emprego da avaliação educacional em larga escala como ferramenta de controle externo e monitoramento da qualidade do ensino, aferida por indicadores quantitativos que permitem a comparação e produção de rankings, e com base nos quais se estabelecem incentivos e sançôes aos docentes e às unidades de ensino (BAUER et al., 2015); a padronização curricular decorrente da adoção desses sistema de avaliação (BONAMINO \& SOUSA, 2012); o enfoque gerencial conferido à administração escolar e a responsabilidade pela combinação dos insumos e pelos resultados educativos atribuída nesse processo aos diretores escolares (OLIVEIRA \& CARVALHO, 2015; PARO, 2015); bem como os deslocamentos das responsabilidades entre os agentes públicos e privados, seja na forma de parcerias (charter schools ou adoção de sistemas de ensino privados), financiamento por bolsas (vouchers) ou cessão da gestão escolar a Organizações Sociais (ADRIÃO, 2015; ROBERTSON \& VERGER, 2012; VISEU, 2014).

Ao longo do presente artigo, procuramos demonstrar, mediante a análise de fluxo das matrículas, organização e tamanho das turmas da rede estadual paulista, que a proposta de reorganizaçáo das unidades de ensino suspensa em 2015 e a gestáo da demanda escolar pela rede estadual paulista em 2016 se enquadram nos moldes da Nova Gestão Pública ${ }^{19}$ (OLIVEIRA, 2015; VERGER \& NORMAND, 2015), e em sua essência consistem em estratégias de racionalização de recursos que operam à revelia de requisitos mínimos de qualidade do ensino público, contribuindo para o seu desprestígio e, consequentemente, atuando a favor dos processos já instalados de privatização do setor.

Nota-se, entretanto, que as justificativas empregadas pela SEE-SP se fundamentam em certas apropriações das projeções demográficas e de uma única versão da noção polissêmica de qualidade do ensino, escamoteando a essência gerencialista das medidas adotadas. Esse é procedimento diverso da reorganização escolar levada a cabo na rede estadual paulista em 1997, que explicitava seus objetivos de racionalização no uso dos equipamentos, na melhoria do planejamento da rede física, no enxugamento da máquina administrativa e no ganho de eficiência em sua gestão (SOUZA, 2002). Além disso, a novidade da fortíssima reação social em defesa de um outro modelo de escola pública obrigou o Estado a um primeiro movimento de recuo, mas ensejou açóes governamentais mais sutis. Daí a importância de, por um lado, demonstrar o sofisma das justificativas baseadas em projeçóes demográficas e, por outro, procurar detectar movimentaçóes que dificilmente seriam publicizadas a tempo e de forma clara.

Esse é mais um dos argumentos em favor da transparência, em nome da qual os dados de demanda e atendimento escolar devem ser disponibilizados 
de forma desagregada e em tempo hábil para a análise independente, servindo ao debate público democrático e plural sobre o ensino e a gestão pública a que aspira a sociedade paulista.

\section{Notas}

1. Os autores participam da Rede Escola Pública e Universidade, que reúne docentes-pesquisadores de instituições públicas de ensino superior paulistas com interesse em constituir um observatório de políticas educacionais visando contribuir para a garantia do direito à educação pública de qualidade no Estado de São Paulo.

2. O Decreto n 61.692 (SÃO PAULO, 2015b) revogou o Decreto nº 61.672 (SÃO PAULO, 2015a), que disciplinava a transferência dos quadros de pessoal entre as unidades escolares que seriam fechadas ou que passariam a atender a um único ciclo, de acordo com a proposta de reorganização divulgada à época.

3. As listas de escolas podem ser consultadas em: Folha de S. Paulo, 28 out. 2015, edição online. Disponível em: <http://www1.folha.uol.com.br/educacao/2015/10/1699674-veja-quais-sao-as-escolas-que-serao-fechadas-no-estado-de-sp.shtml>. Acesso em: 29 jul. 2016.

4. Embora exista controvérsia sobre os testes padronizados como indicadores de qualidade do ensino, há razoável consenso entre estudiosos da avaliaçáo educacional de que a aprendizagem e o desempenho escolar são fenômenos multidimensionais, que não podem ser associados a um fator isolado, sendo necessário controlar variáveis socioeconômicas e territoriais e considerar os numerosos insumos e condiçóes que interferem nos processos educativos, o que requer análise estatística multivariada e interpretação sociológica rigorosa de seus resultados.

5. Conforme a Síntese dos Indicadores Sociais da PNAD 2014 (IBGE, 2015), as taxas de frequência líquida da populaçáo de 6 a 17 anos aos estabelecimentos de ensino no Estado de Sáo Paulo eram, respectivamente, de 92,3\% nos Anos Iniciais do Ensino Fundamental; 87,1\% nos Anos Finais; e 75,8\% no Ensino Médio.

6. Há tempos a administração pública brasileira incorporou o princípio da gratuidade ativa, visando eliminar barreiras que restringem a fruição do direito à educação, o que levou à inscrição da assistência estudantil universal na Constituição Federal, institucionalizando as políticas de alimentação, transporte, saúde e material escolar gratuitos. Tais políticas foram complementadas, na transição do milênio, por programas focalizados de transferência de renda condicionados à frequência escolar. A Lei n 13.005/2014 (BRASIL, 2014) - Plano Nacional de Educação —, por sua vez, menciona estratégias de busca ativa da população que se encontra fora da escola, complementando a determinaçáo de chamada escolar já prevista na Lei de Diretrizes e Bases da Educação Nacional (BRASIL, 1996).

7. A municipalização do Ensino Fundamental no Estado de São Paulo foi impulsionada na segunda metade da década de 1990, sob vigência do Fundo de Manutenção e Desenvolvimento do Ensino Fundamental e de Valorização do Magistério (FUNDEF), pela reorganização da rede estadual implementada na gestão Mário Covas (ADRIÂO, 2008). Já no período de 2007 a 2015, as matrículas 
nos Anos Iniciais do Ensino Fundamental na rede estadual recuaram 35,0\%, e nos Anos Finais diminuíram 27,0\%, ao passo que a expansão do Ensino Médio foi de apenas 4,5\%; no mesmo período, as redes municipais mantiveram estáveis as matrículas nos Anos Iniciais do Ensino Fundamental, mas também perderam 10,0\% de matrículas nos Anos Finais, enquanto a expansão da rede privada registrava crescimento de 32,0\% nos Anos Iniciais e 18,0\% nos Anos Finais do Ensino Fundamental, e incremento de 24,0\% no Ensino Médio (TODOS PELA EDUCAÇÃO, 2016).

8. Resolução $S E n^{\circ}$ 2/2016 (SÃO PAULO, 2016), que substituiu a Resolução SE nº 86/2008 (SÃO PAULO, 2008).

9. Os professores da rede estadual paulista realizaram, no primeiro semestre de 2015 , uma greve que durou 92 dias, e cuja pauta de reivindicaçôes incluía o imediato desmembramento das classes superlotadas e a progressiva redução do número médio de alunos por classe.

10.Cumpre assinalar que esses números excedem os parâmetros mínimos de qualidade estabelecidos pelo Conselho Nacional de Educação no Parecer CEB/CNE nº 8/2010 (CNE; CEB, 2010), que fixa em 24 o número máximo de alunos em classes dos Anos Iniciais do Ensino Fundamental, e 30 alunos em classes dos Anos Finais e do Ensino Médio.

11.No âmbito da Ação Civil Pública (ACP), Proc. nº 1049683-05.2015.8.26.0053.

12.Resposta do Governo do Estado de São Paulo à ACP, Proc. nº 1049683-05.2015.8.26.0053, fls. 880 .

13.Para estimar o número de alunos por classe $(\mathrm{ApC})$, foi utilizado o seguinte procedimento: para cada escola e para cada ano escolar, verificamos no Cadastro o número de classes formadas e o número de alunos, obtendo, assim, a média de alunos por classe associada àquele ano escolar e àquela escola específica. Evidentemente, é possível que haja, em uma mesma escola e em um mesmo ano, classes com mais e com menos alunos, o que não pudemos investigar por não termos à disposição os dados desagregados de cada classe específica. Se essa informação fosse considerada, a dispersão do número de $\mathrm{ApC}$ seria ainda maior do que aquela que obtivemos. Nosso cálculo representa, portanto, um limite inferior para o valor dessa dispersão.

14.A moda corresponde ao número de alunos por classe que é mais frequente em cada etapa ou modalidade investigada (o que corresponde aos valores dos picos em cada gráfico). O fato de haver, na rede estadual, um pequeno número de classes com número de alunos extremamente baixo distorce o significado intuitivo do valor médio, uma vez que ele se torna significativamente mais baixo do que a situaçáo concretamente vivenciada pela maioria dos estudantes. Em situaçôes desse tipo - de distribuiçóes assimétricas - medidas estatísticas como a moda e a mediana permitem uma representação mais realista da situação do conjunto.

15.Se considerarmos o Parecer CNE/CEB n 8/2010 (CNE; CEB, 2010), constatamos que, em 2015 e 2016, respectivamente, 71 e $75 \%$ das turmas formadas na rede estadual paulista excedem os limites de número de alunos por classe recomendados como padráo mínimo de qualidade para a Educação Básica pública no Brasil.

16.A diferença entre o número de aberturas e o número de fechamentos de classes (transição 20152016) com relação ao total de classes existentes em 2015. 
17.Embora no caso dos Anos Finais do Ensino Fundamental (Tabela 5) uma discreta tendência de fechamento seja observada no subconjunto das 361 escolas que se tornariam unidades escolares de EF-AF, também aí a tendência de fechamento de classes nessa etapa de ensino é $66 \%$ menor nesse subconjunto do que na rede toda. Isso indica que foram mantidas mais classes dessa etapa de ensino nesse subconjunto particular do que nas 5.688 unidades escolares da rede que compuseram o universo de escolas investigadas.

18.Essas curvas foram obtidas calculando-se a diferença porcentual entre o número de classes em 2015 e 2016, por etapa de ensino, em cada unidade escolar da rede estadual: as aberturas de classes são representadas por porcentuais positivos, e os fechamentos por porcentuais negativos. As escalas dos gráficos no eixo vertical foram ajustadas, visto que os picos de $0 \%$ (escolas que não fecharam e nem abriram classes de 2015 para 2016) são mais altos que os demais, e poderiam camuflar a visualização das flutuaçóes.

19.A literatura internacional e nacional (DEMAZIÈRE et al., 2013; OLIVEIRA, 2015; VERGER \& NORMAND, 2015; para citar apenas alguns autores) denomina Nova Gestão Pública (NGP) as lógicas globalmente difundidas de racionalização das políticas que, visando à redução das despesas públicas e a ganhos de eficiência na gestão, produziram ao longo das últimas décadas transformaçôes no funcionamento do governo, atribuindo-lhe feiçôes gerenciais (mediante a transposição ao setor público de métodos de gestão do setor privado) e papéis de regulação e avaliaçáo. Apesar da diversidade de implementaçấo nos contextos nacionais, as reformas educacionais orientadas pela NGP apresentam princípios e traços comuns, como: a dissociação das funções de controle e execuçấo, com centralização dos controles e aumento da autonomia e responsabilidade das instâncias descentralizadas de execução pelos resultados; a preeminência das avaliaçôes externas padronizadas como mecanismos de regulação e responsabilizaçáo, com consequências sobre o acesso a recursos e as condições de trabalho docente; o estabelecimento de mecanismos de competição com base no desempenho em avaliaçóes, tomadas como indicadores de qualidade; maior permeabilidade da burocracia à influência dos usuários; restriçóes à autonomia e padronização das práticas profissionais com base em modelos construídos sobre evidências de resultados; terceirização e/ou competição das instituições públicas com aquelas do setor privado para a provisão de serviços.

\section{Referências}

ADRIÃO, T. Oferta do ensino fundamental em São Paulo: um novo modelo. Educação \& Sociedade, Campinas, v. 29, n. 102, p. 79-98, 2008.

ADRIÃO, T.M.F. Dimensões da privatização da educação básica no Brasil a partir de 1990: um diálogo com a produção acadêmica. 2015. Tese (Livre-docência). Faculdade de Educação, Universidade Estadual de Campinas, Campinas.

BAUER, A.; ALAVARSE, O.M.; OLIVEIRA, R.P. Avaliação em larga escala: uma sistematização do debate. Educação e Pesquisa, São Paulo, v. 41, n. especial, p. 1.367-1.382, 2015.

BONAMINO, A.; SOUSA, S.Z. Três gerações de avaliação da educação básica no Brasil: interfaces com o currículo da/na escola. Educação e Pesquisa, São Paulo, v. 38, n. 2, p. 373-388, 2012. 
BRASIL. Emenda Constitucional n ${ }^{\circ} 59$, de 11 de novembro de 2009. Acrescenta $\$ 3^{\circ}$ ao art. 76 do Ato das Disposiçōes Constitucionais Transitórias para reduzir, anualmente, a partir do exercício de 2009, o percentual da Desvinculação das Receitas da União incidente sobre os recursos destinados à manutenção e desenvolvimento do ensino de que trata o art. 212 da Constituição Federal, dá nova redaçáo aos incisos I e VII do art. 208, de forma a prever a obrigatoriedade do ensino de quatro a dezessete anos e ampliar a abrangência dos programas suplementares para todas as etapas da educação básica, e dá nova redação ao $\$ 4^{\circ}$ do art. 211 e ao $₫ 3^{\circ}$ do art. 212 e ao caput do art. 214, com a inserção neste dispositivo de inciso VI. Diário Oficial da União, Brasília, ano 146, n. 216, 12 nov. 2009. Seção 1, p. 8. Disponível em: <http://pesquisa.in.gov.br/imprensa/ jsp/visualiza/index.jsp?jornal=1\&pagina=8\&data=12/11/2009>. Acesso em: 18 nov. 2016.

. Lei no 9.394, de 20 de dezembro de 1996. Estabelece as diretrizes e bases da educação nacional. Diário Oficial da União, Brasília, ano 134, n. 248, 23 dez. 1996. Seção 1, p. 27.83427.841. Disponível em: shttp://pesquisa.in.gov.br/imprensa/jsp/visualiza/index.jsp?

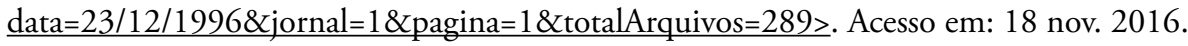

. Lei $\mathrm{n}^{\circ} 12.527$, de 18 de novembro de 2011. Regula o acesso a informaçóes previsto no inciso XXXIII do art. $5^{\circ}$, no inciso II do $\$ 3^{\circ}$ do art. 37 e no $\$ 2^{\circ}$ do art. 216 da Constituiçấo Federal; altera a Lei $n^{\circ} 8.112$, de 11 de dezembro de 1990; revoga a Lei $\mathrm{n}^{\circ}$ 11.111, de 5 de maio de 2005, e dispositivos da Lei no 8.159, de 8 de janeiro de 1991; e dá outras providências. Diário Oficial da União, Brasília, ano 148, n. 221-A, 18 nov. 2011. Seção 1, p. 1-4. Disponível em: shttp://pesquisa.in.gov.br/imprensa/jsp/visualiza/index.jsp?data $=18 / 11 / 2011$ \&jornal=1000\&pagina $=1$ \&totalArquivos=12>. Acesso em: 18 nov. 2016 .

Lei no 13.005, de 25 de junho de 2014. Aprova o Plano Nacional de Educaçáo - PNE e dá outras providências. Diário Oficial da União, Brasília, ano 151, n. 120-A, 26 jun. 2014. Seção 1, p. 1-7. Disponível em: <http://pesquisa.in.gov.br/imprensa/jsp/ visualiza/index.jsp?jornal $=1000$ \&pagina $=1 \&$ data $=26 / 06 / 2014>$. Acesso em: 18 nov. 2016

Portal Brasil. Emprego formal cresce 26,3\% entre 2004 e 2014. 2015. Disponível em: <http:/www.brasil.gov.br/economia-e-emprego/2015/12/emprego-formal-cresce26-3-entre-2004-e-2014>. Acesso em: 18 nov. 2016.

CONSELHO NACIONAL DE EDUCAÇÃO - CNE; CÂMARA DE EDUCAÇÃO BÁSICA - CEB. Parecer CNE/CEB no 8/2010. Estabelece normas para aplicação do inciso IX do artigo $4^{\circ}$ da Lei $n^{\circ} 9.394 / 96$ (LDB), que trata dos padrôes mínimos de qualidade de ensino para a Educação Básica pública. Brasília, DF: Conselho Nacional de Educação/Câmara de Educação Básica, 2010. Disponível em: <http://portal.mec.gov.br/ index.php?option=com_docman\&view=download\&alias=5368-pceb008-10\&category

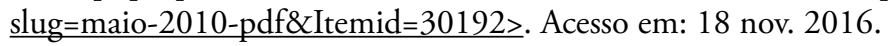

DEMAZIÈRE, D.; LESSARD, C.; MORRISSETTE, J. Introduction: les effets de la Nouvelle Gestion Publique sur le travail des professionnels: transpositions, variations, ambivalences. Education et Sociétés, v. 22, n. 32, p. 5-20, 2013. Disponível em: <http:// www.cairn.info/revue-education-et-societes-2013-2-page-5.htm>. Acesso em: 18 nov. 2016.

DI PIERRO, M.C. O impacto da inclusão da educação de jovens e adultos no FUNDEB no Estado de São Paulo. In: CATELLI JR., R.; HADDAD, S.; RIBEIRO, V.M. (Orgs.). A EJA em xeque: desafios das políticas de educação de jovens e adultos no século XXI. São Paulo: Global/Ação Educativa, 2014. p. 39-76. 
FUNDAÇÃO SISTEMA ESTADUAL DE ANÁLISE DE DADOS - SEADE. Informaçôes dos Municípios Paulistas: IMP. São Paulo: Fundação Sistema Estadual de Análise de Dados, 2016.

Levantamento sobre a evolução das matrículas no ensino básico estadual. São Paulo: Fundação Sistema Estadual de Análise de Dados, set. 2015.

INSTITUTO BRASILEIRO DE GEOGRAFIA E ESTATÍSTICA - IBGE. Censo Demográfico 2010: características da população e dos domicílios - resultados do universo. Rio de Janeiro: IBGE, 2011. Disponível em: <http://biblioteca.ibge.gov. br/visualizacao/periodicos/93/cd 2010 caracteristicas populacao domicilios.pdf $>$. Acesso em: 18 nov. 2016.

. Sintese de Indicadores Sociais: Uma análise das condiçóes de vida da população brasileira 2015. Rio de Janeiro: IBGE, 2015. Disponível em: $\leq$ http://biblioteca.ibge.gov. br/visualizacao/livros/liv95011.pdf>. Acesso em: 18 nov. 2016.

OLIVEIRA, A.C.P.; CARVALHO, C.P. Gestão escolar, liderança do diretor e resultados educacionais no Brasil. In: Reunião Nacional da ANPEd, 37., Florianópolis, 2015. Anais... Florianópolis, 2015.

OLIVEIRA, D.A. Nova gestão pública e governos democrático-populares: contradiçóes entre a busca da eficiência e a ampliação do direito à educação. Educação \& Sociedade, Campinas, v. 36, n. 132, p. 625-646, 2015.

PARO, V.H. Diretor escolar: educador ou gerente? São Paulo: Cortez, 2015.

PAULA, A.P.P. Administração pública brasileira entre o gerencialismo e a gestão social. Revista de Administração de Empresas, v. 45, n. 1, p. 36-49, 2005.

PÓ, M.V.; YAMADA, E.M.K.; XIMENES, S.B.; LOTTA, G.S.; ALMEIDA, W.M. Análise da política pública de Reorganização Escolar proposta pelo governo do Estado de São Paulo. São Bernardo do Campo: Universidade Federal do ABC, nov. 2015. Disponível em: <https:// blogdosalomaoximenes.files.wordpress.com/2015/12/anc3a1lise-da-reorganizac3a7c 3a3o-escolar-sp.pdf>. Acesso em: 29 jul. 2016.

ROBERTSON, S.; VERGER, A. A origem das parcerias público-privada na governança global da educação. Educação \& Sociedade, Campinas, v. 33, n.121, p. 1.133-1.156, 2012.

SANTOS, A.L; GIMENEZ, D.M. Inserção dos jovens no mercado de trabalho. Estudos Avançados, v. 29, n. 85, p. 153-168, 2015.

SÃO PAULO (Estado). Decreto no 61.672. Disciplina a transferência dos integrantes dos Quadros de Pessoal da Secretaria da Educação e dá providências correlatas. Diário Oficial do Estado de São Paulo, Poder Executivo, São Paulo, v. 125, n. 222, 1 dez. 2015a. Seção I, p. 1. Disponível em: shttp://dobuscadireta.imprensaoficial.com.br/default.aspx?.DataP

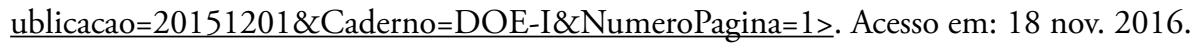

. Decreto no 61.692, de 4 de dezembro de 2015. Revoga o Decreto no 61.672, de 30 de novembro de 2015. Poder Executivo, São Paulo, 2015b. Disponível em: $\leq$ http:// www.al.sp.gov.br/repositorio/legislacao/decreto/2015/decreto-61692-04.12.2015.html>. Acesso em: 18 nov. 2016. 
Secretaria da Educação do Estado De São Paulo. Coordenadoria de Informação, Monitoramento e Avaliação Educacional. Desempenho escolar: estado de São Paulo: 20102013. São Paulo: SEE-SP/CIMA, 2014. Disponível em: <http://www.educacao.sp.gov.br/ a2sitebox/arquivos/documentos/814.pdf>. Acesso em: 29 jul. 2016.

. Escolas estaduais com uma única etapa de atendimento e seus reflexos no desempenho dos alunos. São Paulo: SEE-SP/CIMA, ago. 2015c. Disponível em: $\leq$ http://download.uol.com.br/educacao/2015-documento-reorganizacao-rede-estadualSP.pdf>. Acesso em: 29 jul. 2016.

. Resolução $S E n^{\circ} 2$, de 8 de janeiro de 2016. Estabelece diretrizes e critérios para a formação de classes de alunos, nas unidades escolares da rede estadual de ensino. Diário Oficial do EstadodeSãoPaulo, PoderExecutivo,SãoPaulo,v. 126,n.5,9jan.2016.SeçãoI,p.29.Disponívelem: <https:/www.imprensaoficial.com.br/DO/BuscaDO2001Documento 11 4.aspx?link=/2016/ executivo\%2520secao\%2520i/janeiro/09/pag_0029_F3MM8AAO8235AeFTC3 BJC827JFT.pdf\&pagina $=29 \&$ data $=09 / 01 / 2016 \&$ caderno=Executivo $\% 20 I \&$ pagina ordenacao $=100029>$. Acesso em: 18 nov. 2016.

. Resolução SE no 86, de 28 de novembro de 2008. Dispóe sobre diretrizes e procedimentos para atendimento à demanda escolar nas unidades escolares da Rede Estadual de Ensino. Diário Oficial do Estado de São Paulo, Poder Executivo, São Paulo, v. 118, n. 226, 29 nov. 2008. Seção I, p. 42. Disponível em: <https://www.imprensaoficial.com.br/ DO/BuscaDO2001Documento 11 4.aspx?link=/2008/executivo\%2520secao\%2520i/ novembro/29/pag_0042_8BHPEKCITUP9Re8GITMF6OHOCT6. pdf\&pagina $=42 \&$ data $=29 / 11 / 2008 \&$ caderno $=$ Executivo $\% 20 I \&$ paginaordenacao $=$ 10042>. Acesso em: 18 nov. 2016.

SOUZA, A.N. A racionalidade econômica na política educacional em São Paulo. ProPosiçôes, Campinas, v. 13, n. 1, p. 105-130, 2002.

TODOS PELA EDUCAÇÃO. Análise da evolução do número de matrículas e turmas de ensino fundamental e médio da rede estadual paulista. São Paulo: Todos pela Educação, jun. 2016.

VERGER, A; NORMAND, R. Nueva gestión pública y educación: elementos teóricos y conceptuales para el estudio de un modelo de reforma educativa global. Educação \& Sociedade, Campinas, v. 36, n. 132, p. 599-622, 2015.

VISEU, S. Revisitando o debate sobre o público e o privado em educação: da dicotomia à complexidade das políticas públicas. Ensaio: Avaliação e Políticas Públicas em Educação, Rio de Janeiro, v. 22, n. 85, p. 899-916, 2014.

Recebido em 30 de julho de 2016.

Aprovado em 19 de outubro de 2016. 